\title{
Anatomical, Physiological, and Pharmacological Characteristics of Histidine Decarboxylase Knock-Out Mice: Evidence for the Role of Brain Histamine in Behavioral and Sleep-Wake Control
}

\author{
Régis Parmentier, ${ }^{1}$ Hiroshi Ohtsu, ${ }^{2}$ Zahia Djebbara-Hannas, ${ }^{1}$ Jean-Louis Valatx, ${ }^{1}$ Takehiko Watanabe, ${ }^{2}$ and \\ Jian-Sheng Lin 1 \\ 1/nstitut National de la Santé et de la Recherche Médicale U480, Department of Experimental Medicine, Faculty of \\ Medicine, Claude Bernard University, 69373 Lyon, France, and '2Department of Cellular Pharmacology, Tohoku University, \\ School of Medicine, Aoba-ku, Sendai 980-8575, Japan
}

\begin{abstract}
The hypothesis that histaminergic neurons are involved in brain arousal is supported by many studies. However, the effects of the selective long-term abolition of histaminergic neurons on the sleep-wake cycle, indispensable in determining their functions, remain unknown. We have compared brain histamine (HA)-immunoreactivity and the cortical-EEG and sleep-wake cycle under baseline conditions or after behavioral or pharmacological stimuli in wild-type (WT) and knock-out mice lacking the histidine decarboxylase gene $(\mathrm{HDC}-/-)$. HDC $-/-$ mice showed an increase in paradoxical sleep, a decrease in cortical EEG power in $\theta$-rhythm during waking (W), and a decreased EEG slow wave sleep/W power ratio. Although no major difference was noted in the daily amount of spontaneous W, HDC-/-mice showed a deficit of $\mathrm{W}$ at lights-off and signs of somnolence, as demonstrated by a decreased sleep latencies after various behavioral stimuli, e.g., WT-mice placed in a new environment remained highly awake for 2-3 hr, whereas HDC-/-mice fell asleep after a few minutes. These effects are likely to be attributable to lack
\end{abstract}

of HDC and thus of HA. In WT mice, indeed, intraperitoneal injection of $\alpha$-fluoromethylhistidine (HDC-inhibitor) caused a decrease in W, whereas injection of ciproxifan (HA-H3 receptor antagonist) elicited $W$. Both injections had no effect in HDC-/-mice. Moreover, PCR and immunohistochemistry confirmed the absence of the HDC gene and brain HAimmunoreactive neurons in the $\mathrm{HDC}-/-$ mice. These data indicate that disruption of HA-synthesis causes permanent changes in the cortical-EEG and sleep-wake cycle and that, at moments when high vigilance is required (lights off, environmental change. . .), mice lacking brain $\mathrm{HA}$ are unable to remain awake, a prerequisite condition for responding to behavioral and cognitive challenges. We suggest that histaminergic neurons also play a key role in maintaining the brain in an awake state faced with behavioral challenges.

Key words: wakefulness; sleep-wake cycle; cortical activation; arousal; histaminergic neurons; histamine; histidine decarboxylase knock-out mice; cortical EEG; behavioral challenge
Wakefulness (W) and cortical arousal, defined on the electroencephalogram as low-voltage fast cortical activity, are classically explained by a generally accepted concept, i.e., the reticular ascending activating system initially proposed by Moruzzi and Magoun (1949). According to this, the main ascending excitatory sources originate from neuronal elements within the brainstem reticular formation and transit in the intrathalamic and extrathalamic relays, finally activating the entire cortex by widespread intrathalamocortical and extrathalamocortical systems (Moruzzi, 1972). The importance of the intrathalamocortical system is supported by much recent experimental data (Steriade, 1991), whereas other studies have identified several subcortical structures that serve as the extrathalamocortical systems in cortical

\footnotetext{
Received Feb. 8, 2002; revised June 3, 2002; accepted June 10, 2002.

This work was supported by Institut National de la Santé et de la Recherche Médicale U480 and Claude Bernard University. The doctoral fellowship of R.P. was provided by Ministère de l'éducation nationale, de la recherche et de la technologie du Gouvernement Français. We thank Prof. P. Panula for advice in histamine immunohistochemistry and J. P. Sastre, C. Buda, and G. Guidon for help and skillful technical assistance. We also thank Bioprojet (Paris) for their kind gift of ciproxifan. Some of the preliminary results have been presented at the International Sendai Histamine Symposium (Sendai, Japan, 2000).

Correspondence should be addressed to Dr. Jian-Sheng Lin, Institut National de la Santé et de la Recherche Médicale U480, Département de Médecine Expérimentale, Faculté de Médecine, Université Claude Bernard, 8 avenue Rockefeller, 69373 Lyon Cedex 08, France. E-mail: lin@univ-lyon1.fr.

Copyright (ㄷ) 2002 Society for Neuroscience $0270-6474 / 02 / 227695-17 \$ 15.00 / 0$
}

activation. Among such systems, the basal forebrain has received special attention (Steriade and Buzsaki, 1990; Jones, 2000). In addition, classical and recent studies support a critical role of the posterior hypothalamus and histaminergic neurons in cortical activation and $\mathrm{W}$.

Histaminergic perikarya are found in the tuberomammillary nucleus (TMn) and adjacent areas of the posterior hypothalamus (Panula et al., 1984; Steinbusch et al., 1984; Watanabe et al., 1984; Lin et al., 1986a), a heterogeneous area containing multiple neuronal populations and known to be important in waking mechanisms, because its lesions cause hypersomnia (Moruzzi, 1972; Sakai et al., 1990; Lin, 2000). Histaminergic cells send widespread projections to most cerebral regions, including those known to be important in sleep-wake control, such as the cortex, thalamus, and posterior and preoptic/anterior hypothalamus, and to the forebrain and brainstem aminergic and cholinergic structures (Inagaki et al., 1988; Panula et al., 1989; Lin et al., 1993, 1996). In these target areas, histamine(HA) modulates neuronal activity-excitability via $\mathrm{H} 1, \mathrm{H} 2, \mathrm{H} 3$, and, possibly, unidentified receptors (Schwartz et al., 1991; Haas, 1992; Brown et al., 2001). In freely moving animals, presumed histaminergic neurons discharge tonically and specifically during W (Vanni-Mercier et al., 1984; Sakai et al.,1990; Steininger et al., 1999). Administration of various substances impairing histaminergic transmission increases slow wave sleep (SWS), whereas enhancement of trans- 
mission promotes W (Lin et al., 1988; Monti et al., 1991). Muscimol-induced inactivation of the posterior hypothalamus containing HA cells results in hypersomnia in both normal or experimentally induced insomniac cats (Lin, 2000). Finally, inhibition of HA synthesis in the same area increases SWS, whereas inhibition of HA degradation elicits long-lasting arousal (Lin et al., 1986b, 1988).

These results support the potential importance of histaminergic neurons in arousal, but the effects of selective long-term abolition of HA neurons on the sleep-wake cycle, indispensable in determining their role, remain unknown. Although attempts have been made in cats to abolish neuronal activity in the posterior-hypothalamus either temporarily (Lin et al., 1989) or permanently (Sallanon et al., 1988), these experimental approaches affect not only histaminergic cells, but also nonhistaminergic neurons codistributed in the same or adjacent regions, and so the observed hypersomnia cannot be definitively attributed to the loss of HA cells. Among the nonhistaminergic cells present in the posterior-hypothalamus, a subpopulation, located in the perifornical area, just rostrodorsal to the histaminergic TMn and containing orexin-hypocretin neuropeptides has recently been identified in the mammalian CNS (de Lecea et al., 1998; Sakurai et al., 1998). There is evidence that orexin deficiency might be responsible for the pathogenesis of human and animal narcolepsy (Lin et al., 1999) and that, like HA neurons, orexin-containing cells may be involved in arousal by their widespread projections. It is therefore necessary to clarify the respective role of histaminergic and orexin neurons in sleep-wake control using animal models with selective abolition of each of these systems. In terms of the orexin system, the sleep-wake cycle has been studied in knock-out (KO) (Chemelli et al., 1999) and genetic abolition (Hara et al., 2001) models. As to the HA system, Ohtsu et al. (2001) have recently developed KO mice lacking histidine decarboxylase (HDC), the sole enzyme responsible for HA synthesis, and have demonstrated the absence of HA synthesis in these $\mathrm{HDC}-/-$ mice, thus providing a unique experimental model for determining the impact of long-term selective abolition of the HA system on the sleep-wake cycle. The present study was therefore designed to compare the brain HA system, cortical EEG, and sleep-wake cycle under spontaneous conditions or after behavioral or pharmacological stimuli in wild-type and $\mathrm{HDC}-/-$ mice.

\section{MATERIALS AND METHODS}

\section{Animals and surgery}

Fifteen pairs of male inbred (129/Sv strain) wild-type (HDC+/+ or WT) and histidine decarboxylase gene knock-out (HDC-/- or $\mathrm{KO}$ ) mice were used. The $\mathrm{HDC}-/-$ mice were generated according to previously described procedures (Ohtsu et al., 2001). Briefly, linearized targeting construct was electroporated into R1 embryonic stem cells, derived from 129/Sv embryo (Nagy et al., 1993). The chimeric mice, generated with the confirmed embryonic stem cells, were crossed with $129 / \mathrm{Sv}$ mice to obtain the inbred $+/-$ mice. The animals were kept on $129 / \mathrm{Sv}$ genomic background. All experiments followed EEC Directive (86/609/EEC), and every effort was made to minimize the number of animals used and any pain and discomfort.

At the age of 12 weeks and with a body weight of $27-33 \mathrm{gm}$, the animals were chronically implanted, under deep sodium pentobarbital anesthesia $(60-70 \mathrm{mg} / \mathrm{kg}$, i.p.), with six cortical electrodes (gold-plated tinned copper wire, $\phi=0.4 \mathrm{~mm}$; Filotex, Draveil, France) and three muscle electrodes (fluorocarbon-coated gold-plated stainless steel wire, $\phi=0.03$ $\mathrm{mm}$; Cooner Wire, Chatworth, CA) to record the electroencephalogram (EEG) and electromyogram (EMG) and to monitor the sleep-wake cycle. All electrodes were previously soldered to a multichannel electrical connector, and each was separately insulated with a covering of heat- shrinkable polyolefin-polyester tubing. The cortical electrodes were inserted into the dura through three pairs of holes $(\phi=0.5 \mathrm{~mm})$ made in the skull, located, respectively, in the frontal $(1 \mathrm{~mm}$ lateral and anterior to the bregma), parietal ( $1 \mathrm{~mm}$ lateral to the midline at the midpoint between the bregma and lambda), and occipital ( $2 \mathrm{~mm}$ lateral to the midline and $1 \mathrm{~mm}$ anterior to the lambda) cortices. The muscle electrodes were inserted into the neck muscles. Finally, the electrode assembly was anchored and fixed to the skull with Super-Bond (Sun Medical Co., Shiga, Japan) and dental cement. This implantation allowed stable polygraphic recordings to be made for $>4$ months.

\section{Polygraphic recording and data acquisition and analysis}

After surgery, the animals were housed individually in transparent barrels $(\phi 20 \mathrm{~cm}$, height $30 \mathrm{~cm})$ in an insulated sound-proofed recording room maintained at an ambient temperature of $22 \pm 1^{\circ} \mathrm{C}$ and on a $12 \mathrm{hr}$ light/dark cycle (lights on at 7:00 A.M.), food and water being available ad libitum. In some animals and for some experiments, a video camera with infrared and digital time recording capabilities was set up in the recording room to observe and score the animal's behavior during both the light and dark phases. After a 3-4 d recovery period, the mice were habituated to the recording cable for $10 \mathrm{~d}$ before starting polygraphic recordings.

Cortical EEG (ipsilateral and contralateral frontoparietal and frontooccipital leads) and EMG signals were amplified, digitized with a resolution of 200 and $100 \mathrm{~Hz}$, respectively, and computed on a CED 1401 Plus (Cambridge, UK). Using a Spike2 script and with the assistance of spectral analysis using the fast Fourier transform, polygraphic records were visually scored by $30 \mathrm{sec}$ epochs for wakefulness (W), slow wave sleep (SWS), and paradoxical sleep (PS) according to previously described criteria validated for mice (Valatx, 1971; Valatx and Bugat, 1974).

To avoid any variation caused by the positioning of cortical electrodes, the cortical EEG used for power spectral density analysis was captured from frontoparietal leads, set with reference to the bregma, lambda, and midline in all mice. EEG power spectra were computed for consecutive $30 \mathrm{sec}$ epochs within the frequency range of $0.8-60 \mathrm{~Hz}$ using a fast Fourier transform routine. The data were collapsed in $0.4 \mathrm{~Hz}$ bins. On the basis of visual and spectral analysis, epochs containing artifacts occurring during active waking (with large movements) were visually identified and omitted from the spectral analysis when the threshold value in the $0-1 \mathrm{~Hz}$ band was exceeded; this represented $1.96 \pm 0.94 \%$ of the total recording time. The power densities obtained for each state were summed over the frequency band of $0.8-60 \mathrm{~Hz}$ (total power). To standardize the data, all power spectral densities at the different frequency ranges, i.e., $\delta, 0.8-2.4 \mathrm{~Hz} ; \theta, 3-9 \mathrm{~Hz} ; \alpha$, (spindle) $9-19 \mathrm{~Hz} ; \beta$, $20-30 \mathrm{~Hz} ; \gamma, 30-60 \mathrm{~Hz}$; and $\beta+\gamma, 20-60 \mathrm{~Hz}$, were expressed as a percentage relative to the total power (e.g., power in the $\delta$ range/power in the $0.8-60 \mathrm{~Hz}$ range) of the same epochs. To evaluate contrast in the cortical EEG between SWS and W or PS, we used an EEG power ratio determined by the averaged cortical EEG total power density during SWS divided by that during either W or PS.

\section{Experimental procedures}

In each experiment, recordings were simultaneously made from an equal number (usually in batches of three) of $\mathrm{HDC}-/-$ and $\mathrm{HDC}+/+$ mice. The mice were submitted to the following experimental procedures.

Spontaneous cortical EEG and sleep-wake cycle. During the period of days $15-45$ after surgery, drug-naive mice (11 pairs) were subjected to three separate $24 \mathrm{hr}$ recording sessions, beginning at 7:00 P.M. During each recording session, the animals were left undisturbed. The data from the two sets of mice were then compared.

Cortical EEG and sleep-wake cycle after behavioral stimuli. Recordings were made from $\mathrm{HDC}-/-$ and $\mathrm{HDC}+/+$ mice for $24 \mathrm{hr}$ after each of the three tests described below, which were performed in a random sequence. As a criterion of sedation and drowsiness, the latencies to SWS and PS, defined as the time between the end of the stimuli and the onset of the first SWS or PS episode lasting $>30 \mathrm{sec}$, were also measured. The three tests consisted of: (1) a simulation of injection (at either 10:00 A.M. or 8:00 P.M.; $n=26$ from 13 pairs of animals), consisting of the handling of the animal and sham intraperitoneal injection without needle insertion; (2) a change of litter (at 2:00 P.M.; $n=36$ from 15 pairs of mice), which was a routine care performed at light phase every 4-6 d to clean the cage and which usually causes a period of waking and behavioral excitation in rodents; in this test, we compared the excitability of the two groups of mice following this routine care; (3) a new environment, the 

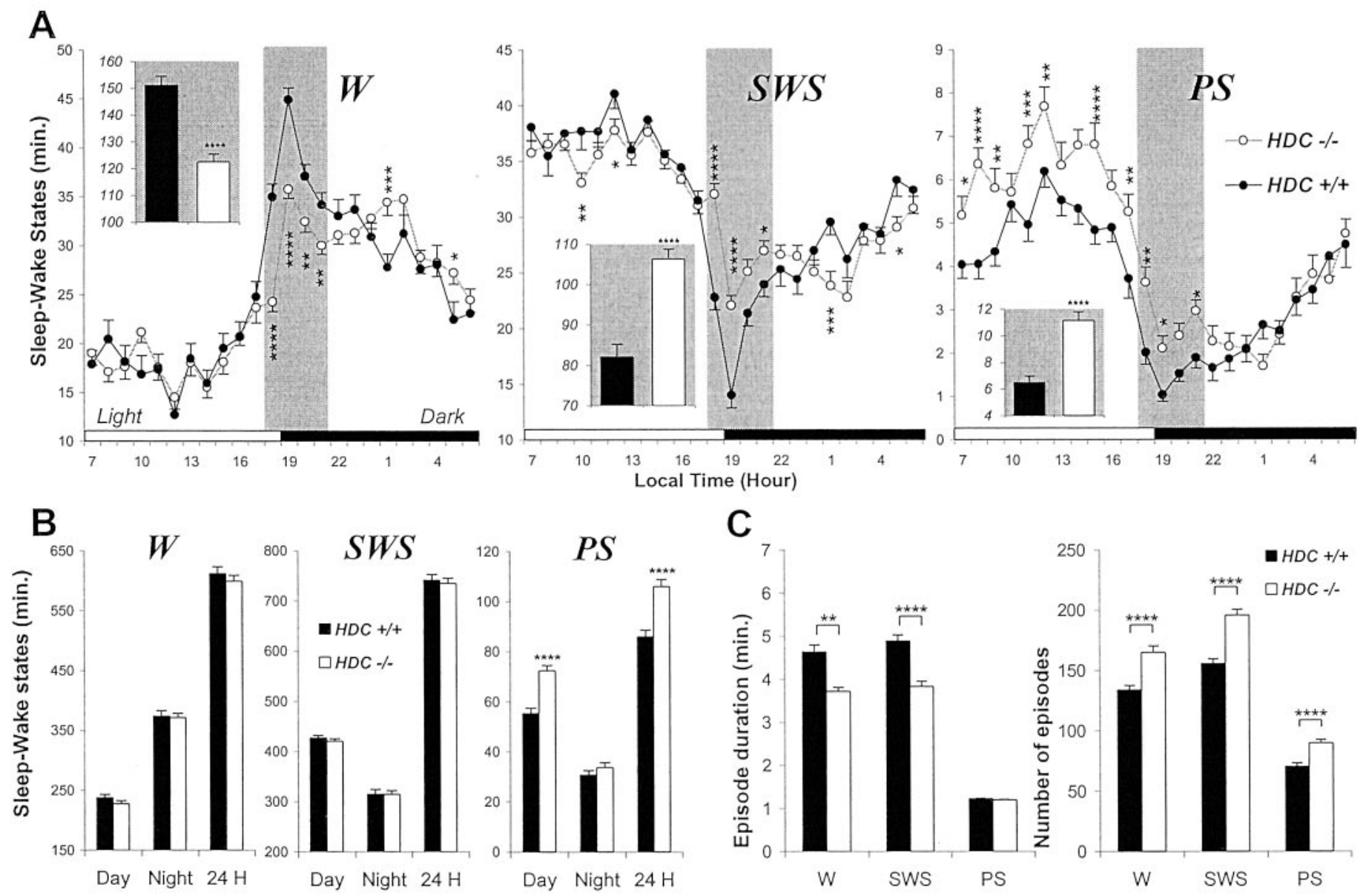

Figure 1. Quantitative comparison of spontaneous sleep-wake parameters in inbred HDC $+/+$ and HDC $-/-$ mice. HDC $+/+$ mice, filled symbols and columns; HDC $-/-$ mice, unfilled symbols and columns. A, Mean hourly values ( $\pm \mathrm{SE})$ of the sleep-wake states. The gray area corresponds to the period between 6:00 and 10:00 P.M., and the total sleep-wake values for each state during this period for both genotypes are indicated in the histogram. $B$, Means ( \pm SE) of sleep-wake stages for the $12 \mathrm{hr}$ light (Day) and dark (Night) periods and the $24 \mathrm{hr}$ period. C, Mean values ( \pm SE) of episode duration and number of episodes of each sleep-wake stage for all $24 \mathrm{hr}$ recordings. Note that, compared with HDC $+/+$ mice, HDC $-/-$ mice exhibit the following: (1) a deficit of W immediately before and after lights-off $(A)$, without major change in the daily amount of W or SWS (B); (2) an increase in PS, mainly in the light phase, because of an increase in the number of episodes $(A-C)$; and (3) a fragmented sleep-wake architecture, with shortened episode duration and increased number of episodes in W and SWS $(C)$. Note also the small interindividual SDs for the sleep-wake stages within each genotype group, indicating that each group was genetically homogenous $(n=33$, corresponding to $3 \times 24$ hr recordings for 11 animals of each genotype). ${ }^{*} p<0.05 ;{ }^{* *} p<0.01 ;{ }^{* *} p<0.001 ;{ }^{* * *} p<0.0001$, using a two-tailed $t$ test after significance in a two-way ANOVA for repeated measures).

mice being transferred for $4 \mathrm{hr}$ from their habitual transparent barrel to an opaque rectangular box $(21 \times 30 \mathrm{~cm}$, height $20 \mathrm{~cm}$, with open field); in this test, the ability of the two genotypes to remain awake after this environmental change was tested. Each mouse was subjected to this test four times separated by an interval of 10-14 d, twice at 2:00 P.M. when the animals normally being sleepy for $\sim 80 \%$ of the time (defined as "sleepy period"; $n=22$ from 11 pairs of mice) (Fig. $1 A$ ), and twice at 6:00 P.M. when they would normally be awake a majority of the time (defined as "awake period"; $n=18$ from nine pairs of mice) (Fig. 1A). Sleep-wake stages during their stay in the new environment were compared between the two groups and with the baseline recordings for the same group.

Cortical EEG and the sleep-wake cycle after drug administration. To compare the effects of drugs acting on the histaminergic system, the two genotypes of mice were injected intraperitoneally with the following agents with an interval of at least $7 \mathrm{~d}$ between injections, subsequent recordings being made for $24 \mathrm{hr}$ : (1) saline alone $(0.1 \mathrm{ml})$ and saline containing $(S)$ - $\alpha$-fluoromethylhistidine $(\alpha-\mathrm{FMH} ; 50 \mathrm{mg} / \mathrm{kg}$; Merck, Sharp, \& Dohme; $n=14$ for each genotype; seven pairs of mice), a specific HDC inhibitor (Kollonitsch et al., 1978; Garbarg et al., 1980; Maeyama et al., 1982); injections were given at 4:00 P.M. (2) Saline alone $(0.1 \mathrm{ml})$ and saline containing cyclopropyl-(4-(3-(1H-imidazol-4-yl) propyloxy) phenyl) ketone (ciproxifan, $1 \mathrm{mg} / \mathrm{kg}$; Bioprojet, Paris, France) $(n=9$ for each genotype; nine pairs of mice), a potent and specific antagonist of histamine-H3 receptor (Ligneau et al., 1998) that controls histamine release and synthesis by autoinhibition; injections were given at 10:00 A.M. (sleepy period). In addition, some animals (nine pairs) were injected subcutaneously with either saline, alone or containing histamine dihydrochloride (HA; Sigma, St. Louis, MO; $1 \mathrm{mg} / \mathrm{kg}$, dissolved in saline and adjusted to $\mathrm{pH} 7$ ) during either the light (10:00 A.M.; $n=9$ ) or dark phase (8:00 P.M.; $n=9$ ) to assess the effect of peripheral HA on the cortical EEG and the sleep-waking cycle. All drugs, expressed as salt weight, were dissolved immediately before use. Results in the saline- and drug-injected animals were compared.

Detection of the HDC gene using the PCR. To confirm the genotypes of the mice used with respect to the HDC gene, at the end of the experiments, tail biopsies were taken from all mice and analyzed by PCR. The WT allele was amplified using primers located within the HDC gene fragment that was replaced by the neomycin resistant gene in the $\mathrm{KO}$ mice. These primers were 5'-AGT GAG GGA CTG TGG CTC CAC GTC GAT GCT-3' (complementary to HDC gene 833-862) and 5'-TAC AGT CAA AGT GTA CCA TCA TCC ACT TGG-3' (HDC gene 980-951), the expected product size being 147 base pairs. The mutant allele was amplified using primers located within the neo ${ }^{\mathrm{r}}$ gene, these being 5'-AAA CAT CGC ATC GAG CGA GCA CGT ACT CGG-3' and $5^{\prime}$-ATG TCC TGA TAG CGG TCC GCC ACA CCC AGC-3', with an expected product size of 244 base pairs. These two sets of primers were included concomitantly and PCR was performed using 40 cycles of 

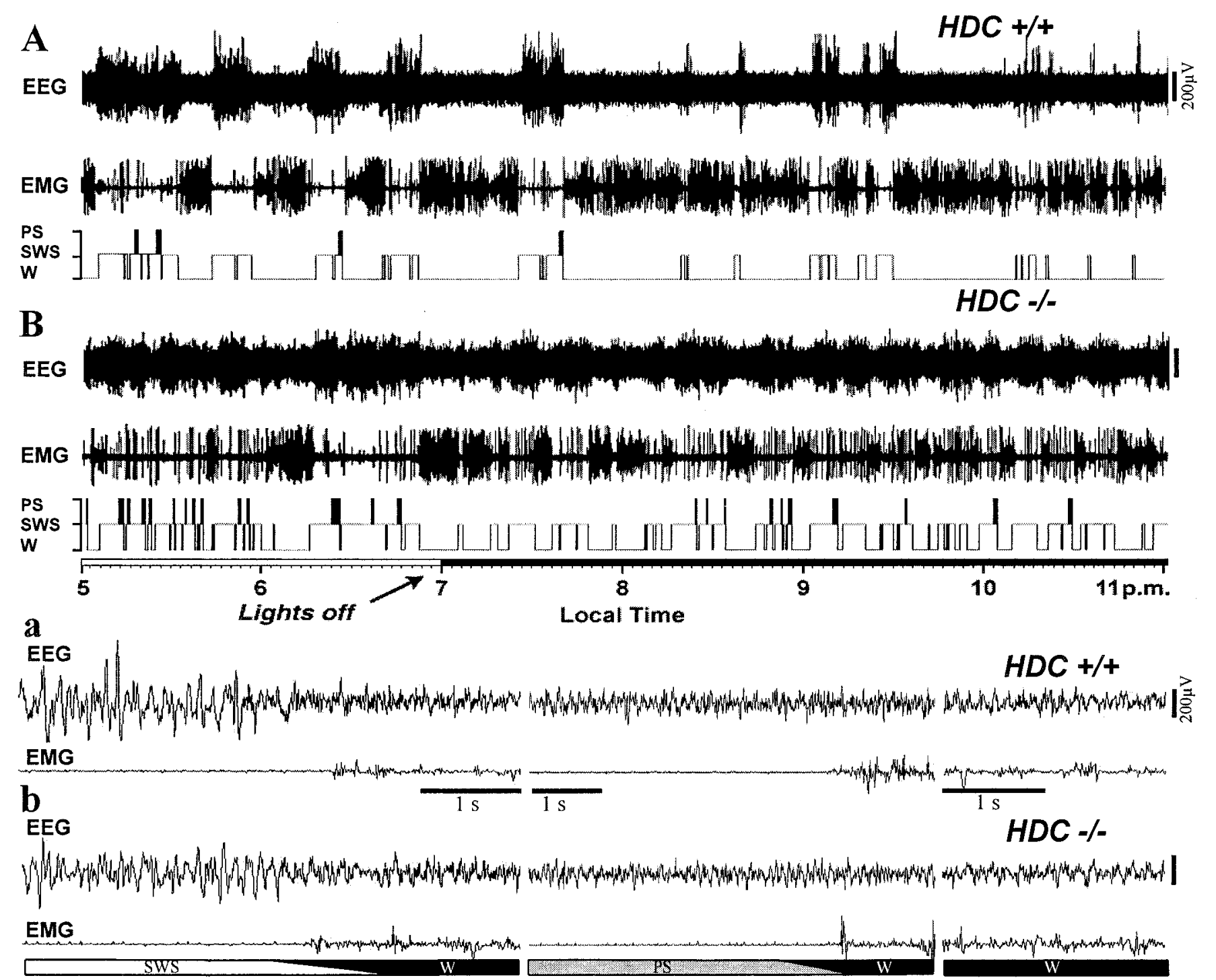

Local Time

$H D C+/+$

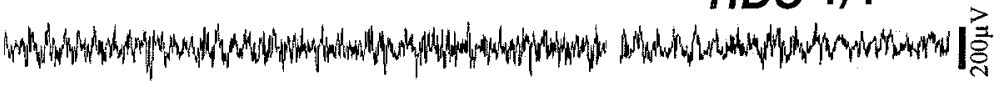
EMG

EEG $\frac{1}{1 \mathrm{~s}}$ $H D C=/-$ EMG

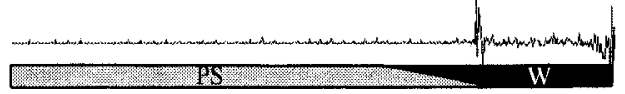

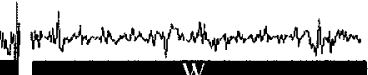

Figure 2. Typical examples of polygraphic recordings and corresponding hypnograms illustrating the spontaneous sleep-wake cycle before and after lights-off and sleep-wake state transitions in HDC $+/+$ and HDC $-/-$ mice. Samples on the hour range $(A, B)$ or second range $(a, b)$ scale from an $\mathrm{HDC}+/+(A, a)$ or HDC $-/-(B, b)$ mouse, showing the following: (1) the cortical EEG signs of both genotypes $(a, b)$; and $(2)$ the decreased waking $(A, B)$ around the lights-off and reduced cortical electroencephalogram (EEG) SWS/W amplitude ratio $(A, B, a, b)$ in the HDC-/- mouse. Calibration: $200 \mu \mathrm{V}, 1$ sec. $E M G$, Electromyogram.

$30 \mathrm{sec}$ at $94^{\circ} \mathrm{C}, 1 \mathrm{~min}$ at $64^{\circ} \mathrm{C}$, and $1 \mathrm{~min}$ at $72^{\circ} \mathrm{C}$, followed by one cycle at $72^{\circ} \mathrm{C}$ for $10 \mathrm{~min}$. The whole reaction mix was then fractionated on a $2 \%$ agarose gel, and the PCR product was visualized by ethidium bromide staining.

Histamine immunohistochemistry. To examine the fate of brain histaminergic neurons after HDC gene disruption, at the end of the other experiments, HA immunohistochemistry was performed as described by Panula et al. (1988), Lin et al. (1993, 1996), and Eriksson et al. (2001). Briefly, the WT and KO animals were anesthetized with an overdose of sodium pentobarbital (>100 mg/kg) and perfused transcardially with 50 $\mathrm{ml}$ of Ringer's lactate solution containing $0.1 \%$ heparin, followed by 60 $\mathrm{ml}$ of ice-cold $0.1 \mathrm{M}$ phosphate buffer (PB), $\mathrm{pH} 7.4$, containing $4 \%$ 1-ethyl-3(3-dimethyl-aminopropyl)-carbodiimide and $0.1 \% \quad N$-hydroxysuccinimide (both from Sigma). After $48 \mathrm{hr}$ postfixation in the same solution and $48 \mathrm{hr}$ rinsing in $\mathrm{PB}$ containing $30 \%$ sucrose and $0.1 \%$ sodium azide, the brains were coronally sectioned ( $25 \mu \mathrm{m}$ thickness) on a freezing cryostat. Free-floating sections were then incubated at $4^{\circ} \mathrm{C}$ for 84-96 hr on an agitator with rabbit anti-HA antibody (Delichon, Masala, Finland) diluted 1:20,000-80,000 in PB saline containing 0.3\% Triton $\mathrm{X}-100$ (PBS-T) and $0.1 \%$ sodium azide. The specificity of the anti-HA antibody has been demonstrated in several species in previous studies
(Panula et al., 1988; Lin et al., 1993, 1996), including mice (Airaksinen et al., 1992). After rinses, the sections were submitted to one of the following procedures:

(1) Some were incubated at $4^{\circ} \mathrm{C}$ overnight on an agitator with $\mathrm{Cy}^{\mathrm{TM}_{3}}$ conjugated anti-rabbit IgG (1: 800; Jackson ImmunoResearch, West Grove, PA) in PBS-T, then immediately mounted on glass slides, and coverslipped with glycerin and examined on a light microscope equipped with epifluorescent illumination with a filter to view $\mathrm{Cy}^{\mathrm{TM}} 3$. A positive reaction was seen as gold-orange fluorescent staining of the labeled structures (see Figs. 11,12).

(2) Others were incubated with either anti-rabbit IgG antibody (1: 1000-2000; Jackson ImmunoResearch, West Grove, PA) or biotinylated anti-rabbit IgG antibody (1: 1000-2000; Vector Laboratories, Burlingame, CA), then, after several rinses, were incubated with rabbit peroxidase-anti-peroxidase (PAP; 1:2000-40,000; Jackson ImmunoResearch) or horseradish peroxidase-conjugated streptavidin (1:40,000; Jackson ImmunoResearch), or a Vectastain ABC kit (1:2000; Vector Laboratories). Both incubations were in PBS-T at $4^{\circ} \mathrm{C}$ overnight on an agitator. The sections were then immersed for 5-10 $\mathrm{min}$ at room temperature in $0.05 \mathrm{M}$ Tris- $\mathrm{HCl}$ buffer, $\mathrm{pH} 7.6$, containing $0.02 \% 3,3^{\prime}$ diaminobenzidine- $4 \mathrm{HCl}, 0.6 \%$ nickel ammonium sulfate, and $0.003 \% \mathrm{H}_{2} \mathrm{O}_{2}$. 


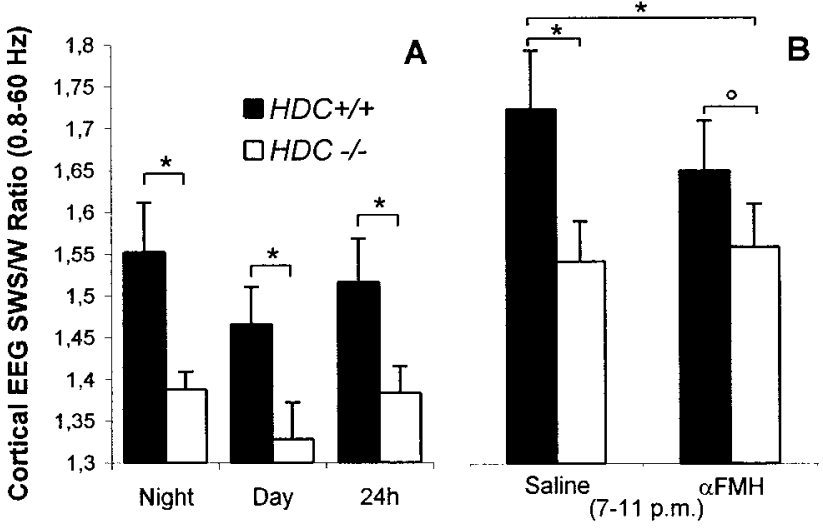

Figure 3. Cortical EEG SWS/W power ratio $(0.8-60 \mathrm{~Hz})$ in $\mathrm{HDC}+/+$ and HDC $-/-$ mice during the night or day periods or over $24 \mathrm{hr}$ of spontaneous recordings or during hours 3-7 after injection of saline or $\alpha$-FMH. Filled columns, HDC $+/+$ mice; unfilled columns, HDC-/mice. $A$, Values of spontaneous recordings $(n=11) ; B$, values of recordings between 7:00 and 11:00 P.M. $(n=14)$ after injection of saline or $\alpha$-FMH $(50 \mathrm{mg} / \mathrm{kg}$, i.p.) at 4:00 P.M. Note the significantly reduced ratio in HDC $-/-$ mice during normal conditions $(A)$ or after saline injection $(B)$, and the lack of a significant difference between $\mathrm{HDC}+/+$ and $\mathrm{HDC}-/-$ mice in the ratio after injection of $\alpha-\mathrm{FMH}(B)\left({ }^{*} p<0.05,{ }^{\circ} p>\right.$ 0.05; two-tailed $t$ test).

A positive reaction resulted in blue-black staining of the labeled structures (somata, dendrites, axons, and varicosities). Some sections were counterstained with neutral red to identify topographic and cellular structures. Finally, all sections were immediately mounted on gelatincoated glass slides, dried, and coverslipped with Depex for light microscopy.

Whereas the biotin-conjugated reagents proved to be incompatible with the carbodiimide-perfused mouse tissue, specific clear labeling was seen using fluorescent staining or nonconjugated $\mathrm{IgG} / \mathrm{PAP}$, and the data presented are those using these methods. The atlas of Franklin and Paxinos (1996) was used for the anatomical nomenclature of cerebral regions and for their abbreviations.

\section{Statistical analysis}

ANOVA and the post hoc Student's $t$ test (two-tailed) were used to evaluate differences between $\mathrm{HDC}+/+$ and $\mathrm{HDC}-/-$ mice in the cortical EEG and sleep-wake parameters under normal conditions or after treatment and differences in these parameters between control data (baseline recordings or saline injection) and data after treatment in the same group of animals; in the latter case, individual animal served as its own control.

\section{RESULTS}

\section{General observations}

As wild-type (WT or $\mathrm{HDC}+/+$ ) mice, HDC gene disrupted (HDC-/- or KO) mice appeared to develop normally. No apparent troubles were noted in terms of fertility, general morphology, movement, or other behaviors under basal conditions. Nevertheless, compared with $\mathrm{HDC}+/+$ animals, $\mathrm{HDC}-/-$ mice seemed to be less reactive when handled, and, at the age of $\sim 12$ weeks, their body weight was greater $(31.6 \pm 0.9 \mathrm{gm}$ at the age of $97 \pm 7 \mathrm{~d} ; n=15$ vs $27.8 \pm 0.5 \mathrm{gm}$ at the age of $93 \pm 3 \mathrm{~d} ; n=15$; $p<0.001$; Student's $t$ test). This difference in body weight increased with age (e.g., the respective weights at 42 weeks were $40.5 \pm 2.6 \mathrm{gm} ; n=11$ vs $33.0 \pm 1.1 \mathrm{gm} ; n=11 ; p<0.02$ Student's $t$ test).

\section{Spontaneous sleep-wake cycle in HDC-/- mice}

Under basal conditions in which the animals were left undisturbed, both sets of mice exhibited a circadian sleep-waking rhythm characteristic of 129/Sv (Huber et al., 2000) and other mice (Franken et al., 1999), i.e., with larger amounts of W during the dark period than during the light one (Fig. 1A,B). Quantitative analysis of the time spent in each sleep-wake stage during the diurnal and nocturnal periods or over $24 \mathrm{hr}$ showed a significantly greater amount of PS in $\mathrm{HDC}-/-$ mice. This increase occurred mainly during the light phase because of an increased number of PS episodes and also led to a PS augmentation of $>23 \%$ over $24 \mathrm{hr}$ (Fig. 1B), PS episode duration remaining unchanged during both light/dark phases (Fig. 1C). No direct onset of PS phases from W was seen in either the lights-on or lights-off period. With respect to $\mathrm{W}$ and SWS, $\mathrm{HDC}-/-$ mice displayed a significant decrease in episode duration and an increase in episode number for both states (Fig. 1C) and during both light/dark phases, e.g., the mean W episode duration over 24 hr was $3.7 \mathrm{~min} \pm 0.1$ instead of $4.6 \mathrm{~min} \pm 0.2$ seen in $\mathrm{HDC}+/+$ mice. However, these changes did not result in a significant change in the total amount of W and SWS during either the light or dark phase or over $24 \mathrm{hr}$ (Fig. 1B).

Despite this lack of a major change in the daily amount of spontaneous $\mathrm{W}$, hourly analysis of sleep-wake states (Fig. 1A) revealed a significantly smaller amount of $\mathrm{W}$ in $\mathrm{HDC}-/-$ mice during the period of 6:00-10:00 P.M, corresponding to the periods before and after lights-off at 7:00 P.M. Thus, like most rodents, the $\mathrm{HDC}+/+$ mice anticipated and responded to lightsoff with a significant increase in W (as a result of increased W episode duration: $6.5 \mathrm{~min} \pm 0.3$ vs $4.6 \mathrm{~min} \pm 0.2$; the mean value over $24 \mathrm{hr} ; p<0.001$ ), accompanied by a high level of behavioral activity, whereas this characteristic phenomenon was markedly reduced or almost absent in the $\mathrm{HDC}-/-$ mice (4.1 \pm 0.1 vs 3.7 $\min \pm 0.1$, the mean value over $24 \mathrm{hr} ; p>0.05$ ) (see Fig. $1 A$ and examples of polygraphic recordings in Fig. $2 A, B$ ). Concomitant to the deficit in $\mathrm{W}$ in $\mathrm{HDC}-/-$ mice $(122.6 \pm 2.8$ vs $151.2 \pm 3.3 \mathrm{~min}$ in HDC $+/+$ mice; $p<0.001)$ there was an increase in both SWS and PS (Fig. $1 A$, boxed areas). The $\mathrm{W}$ deficit during this period was compensated for over $24 \mathrm{hr}$, because there was no major change in the daily total W (Fig. 1B).

Because an age-related increase in body weight was found in HDC $-/-$ mice and to determine the possible effect this might have on the sleep-wake cycle or vice versa, we also examined the relationship between body weight and sleep-wake parameters in all mice. No correlation was found between body weight (at age of 12 weeks) and the daily amount of sleep-wake stages in either genotype, except for a negative correlation with PS (linear regression, $p=0.034$ ) in the $\mathrm{HDC}-/-$ group. At the age of $\geq 40$ weeks, the body weight of $\mathrm{HDC}-/-$ mice increased significantly, whereas their daily amount of PS remained unchanged (data not shown). These data indicate that there is no simple causal link between body weight and the sleep-wake change seen in HDC $-/-$ mice. Further studies, such as controlling the animal's food intake, activity, and metabolism, are required to determine the mechanisms by which $\mathrm{HDC}-/-$ mice regulate their body weight.

\section{Characteristics of cortical EEG in HDC-/- mice}

From the frontoparietal leads (Fig. 2; see Fig. 4) as the frontooccipital ones (data not shown), the cortical EEG of both sets of animals manifested marked and specific changes across the behavioral states and signs characteristic of mice, i.e., with dominant presence of $\theta$ frequencies, notably during PS and W. Nevertheless, compared with $\mathrm{HDC}+/+$ ones, $\mathrm{HDC}-/-$ mice showed changes in the following aspects: 


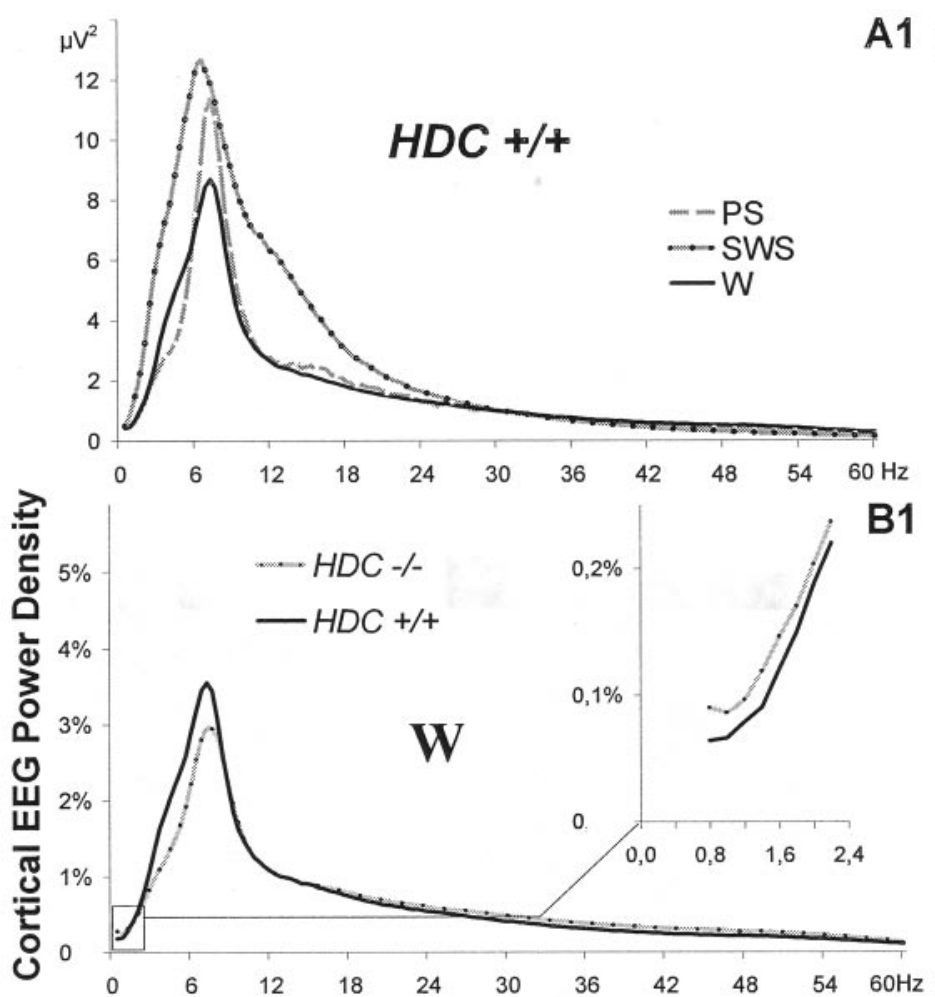

A1 $\mu \mathrm{V}^{2}$
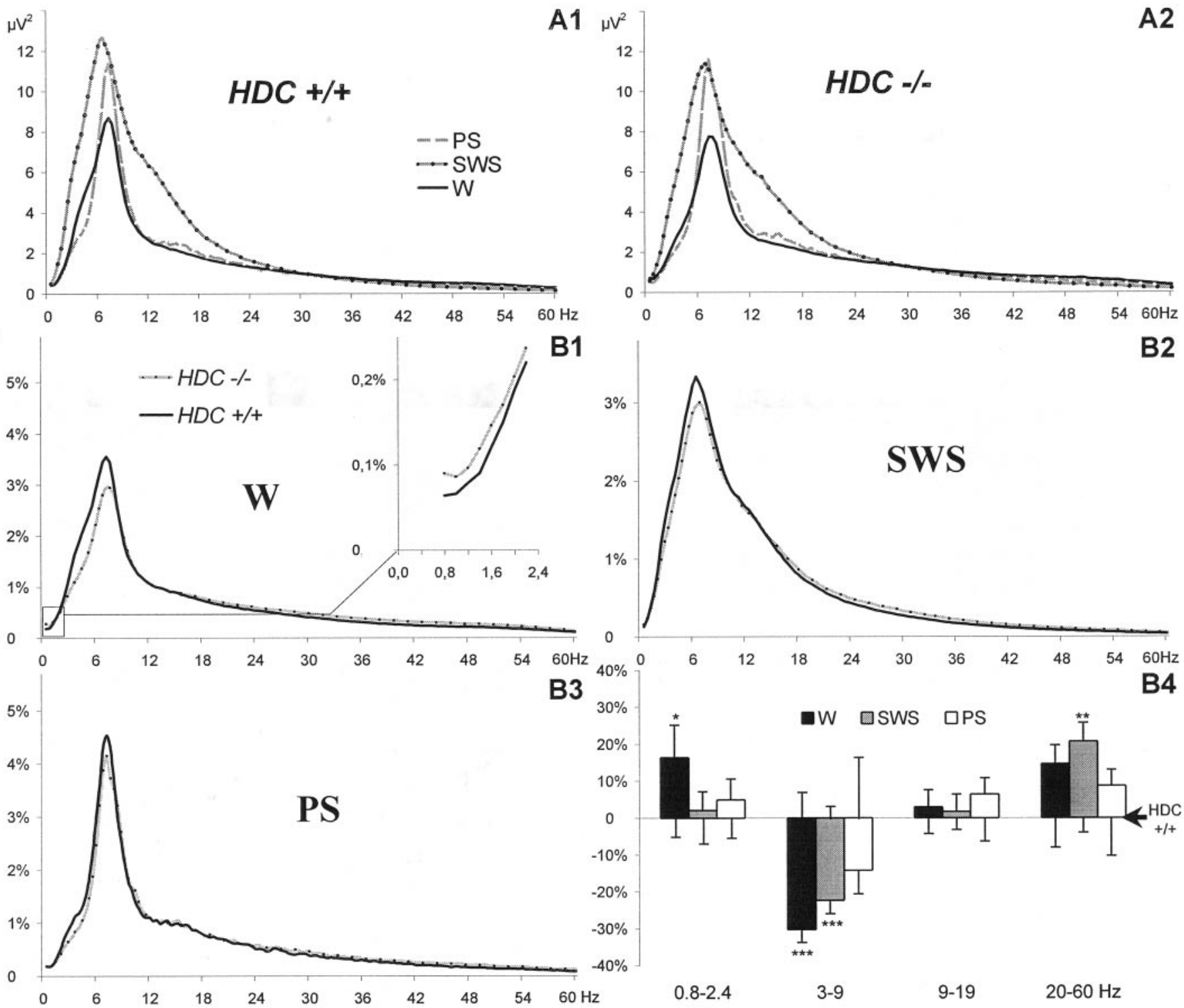

Figure 4. Mean spectral distribution of cortical EEG power density in spontaneous sleep-wake states in inbred HDC $+/+$ and HDC $-/-$ mice. The data were obtained from 14 pairs of animals by pooling consecutive $30 \mathrm{sec}$ epochs during the period of 7:00-10:00 P.M. using the fast Fourier transform routine within the frequency range of $0.8-60 \mathrm{~Hz}$. $A 1, A 2$, Mean absolute power values (in square microvolts) in each $0.4 \mathrm{~Hz}$ frequency bin. Note the state-dependent profiles of cortical EEG spectra across wakefulness $(W)$, slow wave sleep $(S W S)$, and paradoxical sleep $(P S)$ in HDC $+/+(A 1)$ and HDC $-/-(A 2)$ mice. B1-B3, Mean percentage power density calculated as the mean power (in square microvolts) in each $0.4 \mathrm{~Hz}$ frequency bin divided by the total power $(0.8-60 \mathrm{~Hz})$ in the same epoch. The spectra from HDC+/+ mice were set to the same apparent sizes to those of the same animals in $A 1$ to facilitate comparison. The inset on $B 1$ is enlarged view for $0.8-2.4 \mathrm{~Hz}$. B4, EEG power spectra in HDC-/- mice (columns, $n=14)$ expressed as a mean percentage change $( \pm \mathrm{SE})$ relative to those $( \pm \mathrm{SE})$ in $\mathrm{HDC}+/+$ mice (baseline $0 ; n=14)$. Note that the HDC $-/-$ mice show an increase in power density of cortical $\delta$ frequency $(0.8-2.4 \mathrm{~Hz})$ during W, a deficit of power density of cortical slow $\theta$ rhythm $(3-9 \mathrm{~Hz})$ during W and SWS, and an increase in power density of cortical fast rhythms $(\beta+\gamma, 20-60 \mathrm{~Hz})$ during SWS $\left({ }^{*} p<0.05\right.$; $* *<<0.01$; *** $p<0.001$; two-tailed $t$ test).

\section{A reduced cortical EEG $S W S / W$ power ratio}

As shown in Figure 2 (see also Figs. 5, 8), one remarkable and visually detectable change in the cortical EEG in HDC- - - mice was a reduction in the EEG SWS/W amplitude ratio. This observation is confirmed by an analysis of the averaged cortical EEG SWS/W power $(0.8-60 \mathrm{~Hz})$ (Fig. $3 A$ ) showing that, in $\mathrm{HDC}+/+$ mice, the power ratio was higher during the darkness than during the light phase, with the maximal ratio found around lights-off (4:00-10:00 P.M.) (Fig. 3B), and that the ratio in HDC-/- mice was significantly lower than that in $\mathrm{HDC}+/+$ mice, during either phase or over $24 \mathrm{hr}$ (Fig. 3A). This decreased ratio was seen during all recorded baseline periods (i.e., days 15-45 after sur- gery). The reduced SWS/W power ratio was mainly attributable to a reduced peak power and amplitude of the cortical EEG of SWS. Although these parameters also decreased during W, that could not contribute to such a reduced ratio (Fig. 4). In addition, the cortical EEG SWS/PS power ratio was also lower in HDC $-/-$ mice (data not shown). Because of these changes in the cortical EEG desynchronization/synchronization power ratios in HDC $-/-$ mice, we then analyzed each cortical EEG frequency during all sleep-wake states in both $\mathrm{HDC}+/+$ and $\mathrm{HDC}-/-$ mice. As shown in Figure 4, $A 1$ and $A 2$, both genotypes displayed state-dependent cortical EEG spectral profiles, with peak powers of W, SWS, and PS similar to those reported for the $129 / \mathrm{Sv}$ 
Table 1. Mean latencies ( \pm SE) to slow wave sleep (SWS) and paradoxical sleep (PS) in HDC+/+ and HDC-/- mice after behavioral challenge or drug administration

\begin{tabular}{|c|c|c|c|c|c|}
\hline & & \multicolumn{2}{|c|}{ Latencies to SWS (min) } & \multicolumn{2}{|c|}{ Latencies to PS (min) } \\
\hline & & $\mathrm{HDC}+/+$ & $\mathrm{HDC}-/-$ & $\mathrm{HDC}+/+$ & $\mathrm{HDC}-/-$ \\
\hline Simulation of injection & $(n=26)$ & $15.7 \pm 1.3$ & $9.9 \pm 1.1^{* *}$ & $48.7 \pm 8.5$ & $23.8 \pm 2.5^{*}$ \\
\hline Litter change & $(n=36)$ & $25.1 \pm 1.2$ & $14.9 \pm 1.1^{* * * *}$ & $50.1 \pm 2.8$ & $37.8 \pm 2.8^{* *}$ \\
\hline Environmental change at 2:00 P.M. & $(n=18)$ & $42.5 \pm 8.9$ & $18.4 \pm 1.8^{* * *}$ & $91.0 \pm 9.3$ & $51.3 \pm 4.2^{* * *}$ \\
\hline Return to home cage & & $16.2 \pm 3.7$ & $12.4 \pm 1.8$ & $28.5 \pm 9.3$ & $21.0 \pm 2.3$ \\
\hline Environmental change at 6:00 P.M. & $(n=22)$ & $35.7 \pm 6.5$ & $15.3 \pm 1.5^{* *}$ & $109.6 \pm 14.3$ & $49.0 \pm 4.6^{* * *}$ \\
\hline Return to home cage & & $19.2 \pm 1.4$ & $17.6 \pm 2.2$ & $39.9 \pm 2.9$ & $32.1 \pm 2.4$ \\
\hline Ciproxifan $1 \mathrm{mg} / \mathrm{kg}$ i.p. & $(n=9)$ & $53.7 \pm 7.2^{\circ 000}$ & $11.1 \pm 3.4^{* * * *}$ & $91.1 \pm 13.5^{\circ 00}$ & $30.3 \pm 4.6^{* * * *}$ \\
\hline$\alpha \mathrm{FMH} 50 \mathrm{mg} / \mathrm{kg}$ i.p. & $(n=14)$ & $12.4 \pm 2.6$ & $8.8 \pm 2.2$ & $46.8 \pm 4.6$ & $35.0 \pm 3.9^{*}$ \\
\hline
\end{tabular}

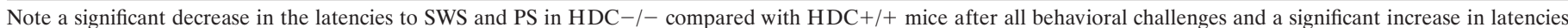

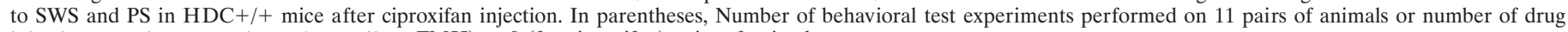
injection experiments performed on 7 (for $\alpha \mathrm{FMH}$ ) or 9 (for ciproxifan) pairs of animals.

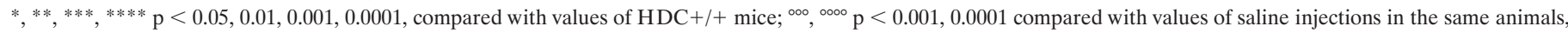
two-tailed $t$ test after significance in two-way ANOVA for repeated measures.

(Huber et al., 2000), 129/Ola, or DBA/2J (Franken et al., 1998) strains. When the power spectral density in each $0.4 \mathrm{~Hz}$ bin/total power $(0.8-60 \mathrm{~Hz})$ of each $30 \mathrm{sec}$ epoch was compared between the genotypes (Fig. 4B1-B4), we found further changes in the HDC $-/-$ mice:

An increased power density of cortical activity in $\delta$ range during $W$

This increase, limited to the slow $\delta$ range $(0.8-2.4 \mathrm{~Hz})$, was seen only during W (Fig. 4B1, B4).

A decrease in the power density of cortical $\theta$ rhythm (3-9 Hz) This was most marked during $\mathrm{W}$, less prominent during SWS, and not significant during PS (Fig. 4B1-B4). This deficit of $\theta$ rhythm appears to contribute largely to the decrease in the peak power and amplitude of the cortical EEG of W and SWS (Fig. 4).

An increase in the power density of cortical fast rhythm ( $\beta$ and $\gamma$ ranges, 20-60 Hz) during SWS (Fig. 4B2,B4)

A smaller increase was also seen during PS and W, but did not reach statistical significance. No major change was seen in power density in the spindle or $\alpha$ frequencies (including the $9-19 \mathrm{~Hz}$ range) during any state (Fig. 4B1-B4).

\section{Effects of behavioral stimuli on sleep latencies and the sleep-wake cycle}

Consistent with the observation that $\mathrm{HDC}-/-$ mice were less reactive when handled, three behavioral tests confirmed an objective sedative behavior in these mice.

Recordings of sleep-wake parameters after a routine litter change during the light phase or after a behavioral challenge, such as a simulation of injection, during either the light or dark phase showed significant shorter latencies to SWS and PS in HDC $-/-$ mice than in $\mathrm{HDC}+/+$ mice (Table 1$)$. There were however, no major differences between the two genotypes in the sleep-wake cycle after sleep onset (data not shown).

A greater difference in the sleep-wake cycle was seen between the two genotypes in the new environment test, which consisted of transferring the mice from their habitual home cage (a transparent barrel) to a new cage (an opaque rectangular box with open field). Thus, as shown in Figures 5 and 6 and Table 1, the transfer of the $\mathrm{HDC}+/+$ mice to the new cage elicited an increase in $\mathrm{W}$ over the whole $4 \mathrm{hr}$ period that the mice were in the new cage, including a significant increase in the latencies to SWS and
PS (Table 1) and an increase in W and decrease in SWS after sleep onset during their stay in the new cage (Figs. 5, 6). They appeared to be interested by the new environment, because video recording showed several exploratory behaviors, such as ambulation around the new cage and rearing. In contrast, $\mathrm{HDC}-/-$ mice seemed indifferent and unresponsive, because they fell asleep soon after the environmental change (Fig. 5, Table 1), and there was no change in $\mathrm{W}$ and SWS during their $4 \mathrm{hr}$ stay in the new cage, compared with their own control data during basal conditions (Fig. 6). This difference in responsiveness to the new environment was seen both at 2:00 P.M. (sleepy period; Fig. 5, top panels, Table 1), and at 6:00 P.M. (awake period; Fig. 5, bottom panels, Table 1). Both sets of mice showed a decrease of $\sim 4-8$ min in PS in the new environment compared with their baseline recordings (Fig. 6) in which they were undisturbed, presumably as a result of handling. Interestingly, when the animals were placed back to their home cages after the $4 \mathrm{hr}$ stay, no any significant difference in term of sleep latencies was noted between the two genotypes (Table 1), suggesting that novelty plays an important role in the new environment-elicited awakening in the $\mathrm{HDC}+/+$ mice. It should be mentioned that the object recognition test showed that the vision of both phenotypes was intact and that the mice appeared not to be stressed during their stay in the new cage, because a similar degree of water and food intake and grooming occurred as in the home cage. No immobility or hyperactivity or other apparently unusual behavioral signs were seen, suggesting that the animals did not suffer stress or anxiety in the new environment.

\section{Effects of drug administration on the cortical EEG and sleep-wake cycle} $\alpha-F M H$

Before and after lights-off, $\mathrm{W}$ and locomotion increased in the $\mathrm{HDC}+/+$ mice, whereas these effects were markedly less evident in $\mathrm{HDC}-/-$ mice. When the animals were injected intraperitoneally with $\alpha$-FMH (specific HDC inhibitor, $50 \mathrm{mg} / \mathrm{kg}$,) at 4:00 P.M. (3 hr before lights-off, in view of the latency of drug action shown in Garbarg et al., 1980; Maeyama et al., 1982), a progressively developing significant decrease in $\mathrm{W}$ and increase in both SWS and PS were seen in $\mathrm{HDC}+/+$ mice (Fig. 7, left plots), results similar to the reduction in $\mathrm{W}$ seen in untreated $\mathrm{HDC}-/-$ mice during this period under basal conditions. The increase in SWS and PS was caused by a prolongation of episode duration 


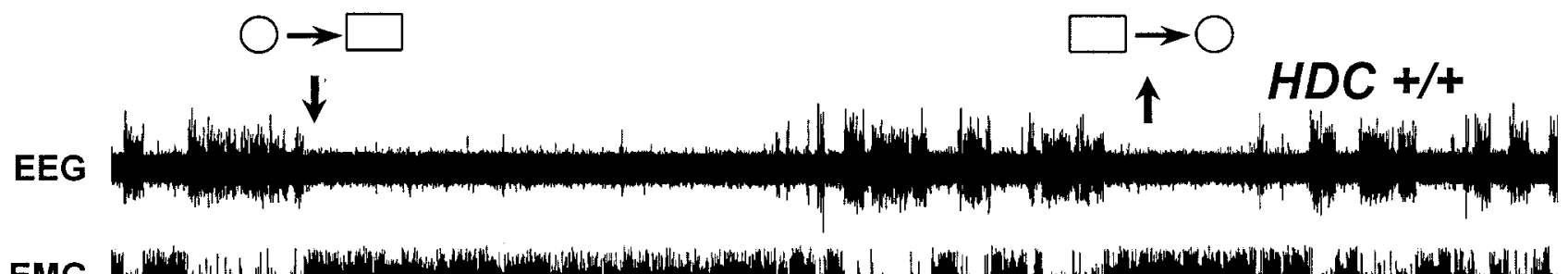

EMG

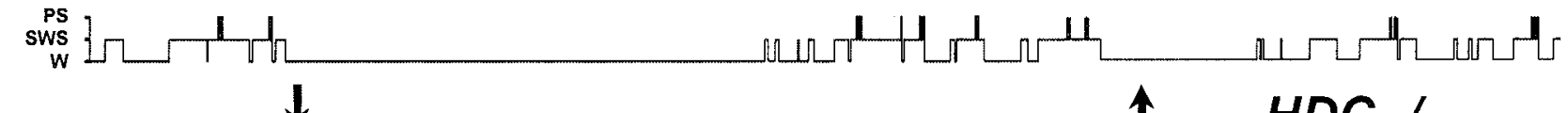

EEG

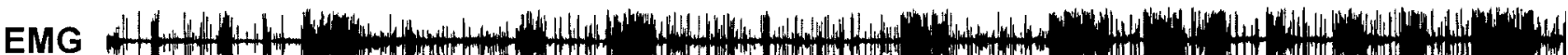

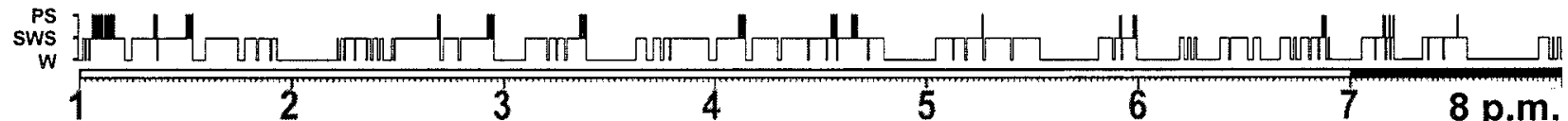

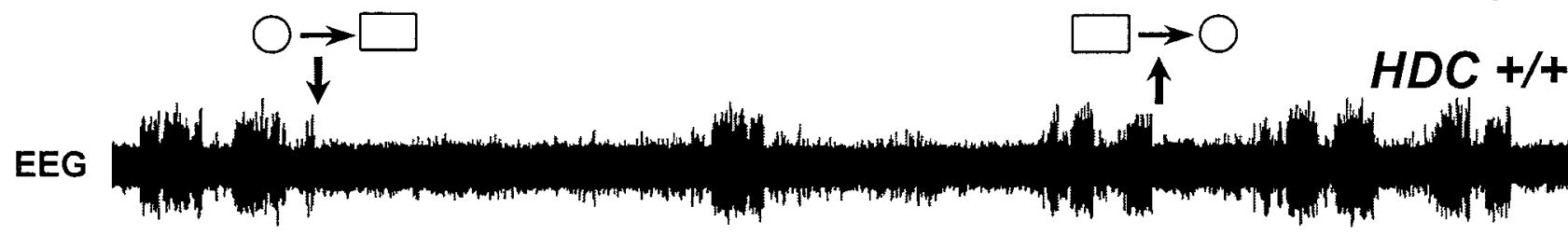

EMG

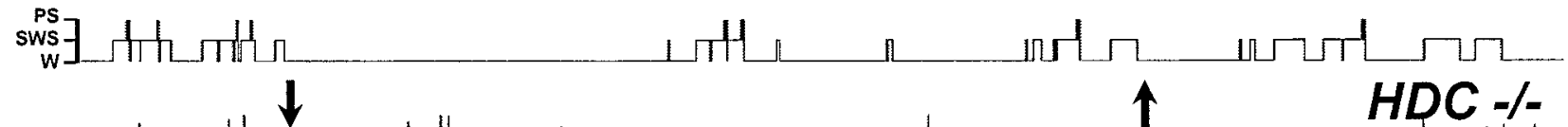

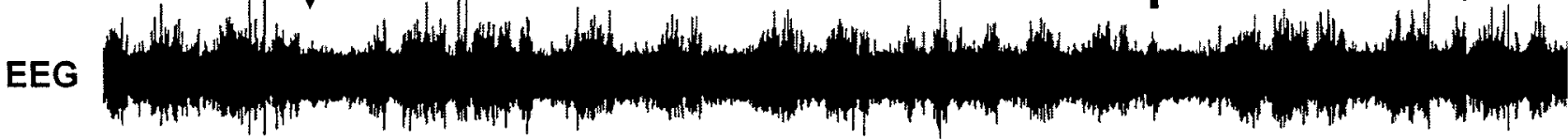
EMG

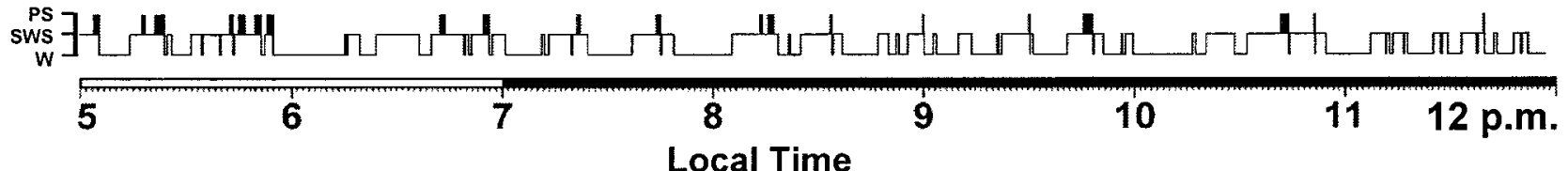

Figure 5. Typical examples of polygraphic recordings and corresponding hypnograms illustrating the effects of an environmental change on HDC $+/+$ and HDC $-/-$ mice. The environmental change (indicated by an arrow) consisted of moving the animals from their habitual transparent barrel cages to opaque rectangular cages at either 2:00 P.M. (sleepy period; top panels) or 6:00 P.M. (awake period; bottom panels). Note that the HDC $+/+$ mouse remained awake for $>2 \mathrm{hr}$ in the new environment, whereas the $\mathrm{HDC}-/-$ mouse fell asleep soon after the test.

(data not shown). In contrast, $\alpha$-FMH injection had no effect on either W, SWS, or PS in HDC-/- mice, (Fig. 7, right plots). The latency to SWS after injection was not significantly different between the two genotypes, whereas that to PS was significantly shorter in $\mathrm{HDC}-/-$ mice, similar to that seen with a simulation of injection (Table 1). It can be mentioned here that $\alpha$-FMH at a smaller dose $(20 \mathrm{mg} / \mathrm{kg})$ in cats (Lin et al., 1988) and rats (Monti et al., 1988) results in a similar increase in SWS to that seen here in $\mathrm{HDC}+/+$ mice, but the effect is not accompanied by an increase in PS; whereas a delayed (latency $>16 \mathrm{hr}$ ) increase in PS is seen in rats using a larger dose $(100 \mathrm{mg} / \mathrm{kg}$; Kiyono et al.,
1984). It remains to determine whether the previous negative results on PS were attributable to incomplete inhibition of the HA synthesis.

Concomitant with the behavioral activation before and after lights-off in $\mathrm{HDC}+/+$ mice, the cortical EEG SWS/W power ratio was highest during this period (Fig. $3 B$ ). As in other circadian periods, the cortical-EEG SWS/W power ratio in $\mathrm{HDC}-/-$ mice during this period was significant lower than that in $\mathrm{HDC}+/+$ mice. $\alpha-\mathrm{FMH}$ injection had no effect on this ratio in $\mathrm{HDC}-/-$ mice, but reduced it in $\mathrm{HDC}+/+$ mice, with the result that, after injection, there was no longer significant difference 

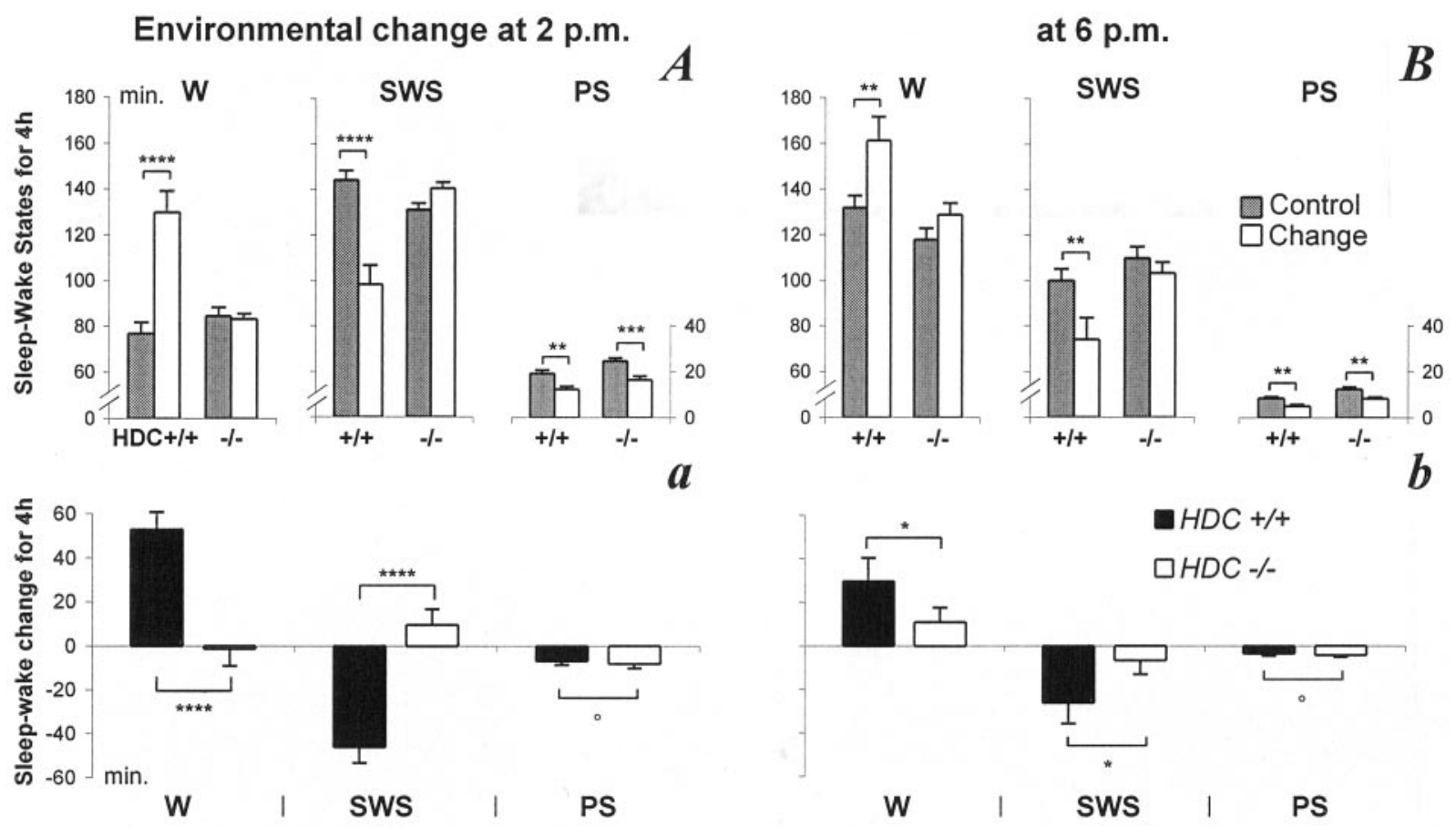

Figure 6. Quantitative variations of sleep-wake states in $\mathrm{HDC}+/+$ and $\mathrm{HDC}-/-$ mice after an environmental change. Top histograms $(A, B)$, Mean values ( \pm SE in minutes) of each sleep-wake stage during the $4 \mathrm{hr}$ in which the animals were in the new environment compared with the baseline recordings for the same group. Bottom histograms $(a, b)$, Sleep-wake changes (in minutes) relative to the baseline value for the same group. Left histograms $(A, a)$, Environmental change at 2:00 P.M.; right histograms $(B, b)$, change at 6:00 P.M. Note the significant increase in waking $(W)$ and decrease in slow wave sleep $(S W S)$ in HDC $+/+$ mice compared either with their own baseline values $(A, B)$ or the values $(b o t t o m, a, b)$ for HDC-/mice $\left(n=18\right.$ at 2:00 P.M. and 22 at 6:00 P.M. from 9 and 11 pairs of animals). $P S$, Paradoxical sleep; ${ }^{\circ} p>0.05 ;{ }^{*} p<0.05,{ }^{* *} p<0.01,{ }^{* * *} p<0.001$, $*_{* * *} p<0.0001$, two-tailed $t$ test after significance in a two-way ANOVA for repeated measures.

between the two genotypes in the cortical EEG SWS/W power ratio (Fig. 3B).

\section{Ciproxifan}

In $\mathrm{HDC}+/+$ mice, intraperitoneal injection of ciproxifan $(1 \mathrm{mg} /$ $\mathrm{kg}$ ), a potent and specific HA-H3 receptor antagonist (Ligneau et al., 1998) at the light phase (10:00 A.M.) caused suppression of cortical slow activity $(\delta+\theta$ ranges) and spindles $(8-14 \mathrm{~Hz})$, resulting in a state of total cortical activation (Fig. 8), i.e., lowvoltage electrical activity with dominant waves in the $\beta$ and $\gamma$ bands $(20-60 \mathrm{~Hz})$. Furthermore, ciproxifan injection increased the power density of these neocortical fast rhythms (Fig. 8). The effects on the cortical EEG were manifested on polygraphic scoring as an almost total waking state, characterized by a significantly delayed sleep latency (Table 1) and suppression of SWS and PS, followed by an increase in W after sleep onset, lasting $>4$ hr (Figs. 8, 9).

In HDC $-/-$ mice, the same injection of ciproxifan had no significant effect on either the cortical EEG or the sleep-wake states compared with saline injection of the same animals (Figs. 8, 9).

\section{Histamine dihydrochloride}

To assess and compare the influence of peripheral HA, which does not pass through the blood-brain barrier (Schwartz et al., 1991), on the cortical EEG and sleep-wake cycle in $\mathrm{HDC}+/+$ and $\mathrm{HDC}-/-$ mice, HA was injected subcutaneously during the dark (8:00 P.M.; $n=9$ ) or light phase (10:00 A.M.; $n=9)$. HA at a dose of $1 \mathrm{mg} / \mathrm{kg}$ had no significant effect on either the cortical EEG or the sleep-wake states in either genotype compared with saline injection ( $n=9$ at either 10:00 A.M. or 8:00 P.M.) of the same animals (data not shown).

\section{Genotype confirmation by PCR}

At the end of the experiments, to confirm the HDC genotypes of the mice, we performed PCR on genomic DNA from tail biopsies from all 15 mice in each group. As shown in Figure 10, a strong HDC signal, corresponding to a 147 base pair band, was detected in the $\mathrm{HDC}+/+$ mice (animals $16-30$ in Fig. 10), and a strong $\mathrm{Neo}^{\mathrm{r}}$ signal, corresponding to a 244 base pair band, was detected in the $\mathrm{HDC}-/-$ mice (animals 1-15), proof that, in the $\mathrm{KO}$ animals, the HDC gene had indeed been disrupted and the $\mathrm{Neo}^{\mathrm{r}}$ gene inserted.

\section{Histology and histamine immunohistochemistry}

Because the HA system in the mouse brain has not been fully described in the literature, at the end of the experiments, we performed HA immunohistochemistry and examined the distribution of histaminergic cell bodies and fibers throughout the brain in both genotypes to determine the fate of brain histaminergic neurons after HDC gene disruption.

$\mathrm{HDC}+/+$ mice

Similar to results in the cat (Lin et al., 1986a, 1993), rat (Panula et al., 1984; Steinbusch and Mulder; 1984; Watanabe et al., 1984), guinea pig (Airaksinen and Panula, 1988), and mouse (Airaksinen et al., 1992), in the $\mathrm{HDC}+/+$ mice, HA-immunoreactive neurons were located almost exclusively in the posterior hypothalamus; a few appeared more rostrally, restricted to a region dorsal to the optic tract in the anterior hypothalamus, whereas 


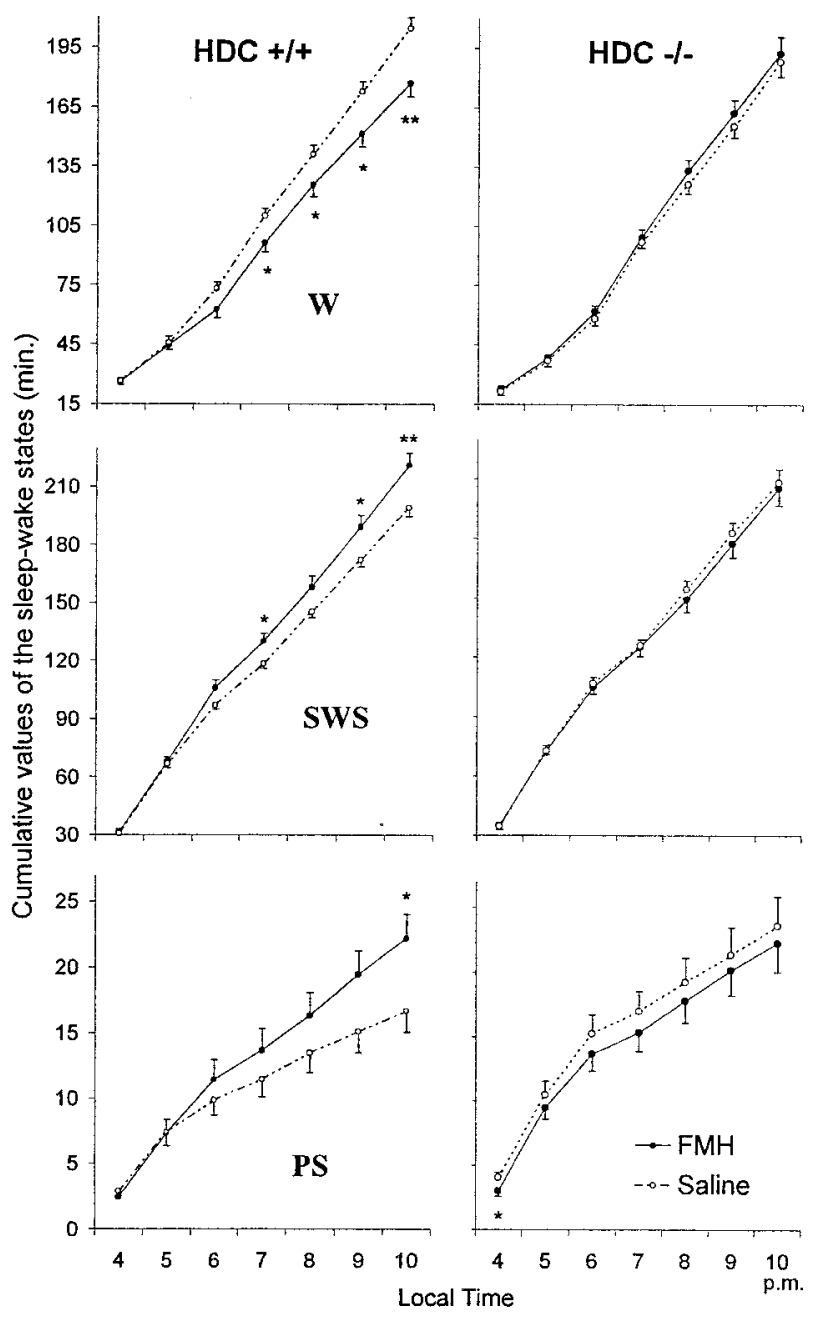

Figure 7. Effects of $\alpha$-FMH on sleep-wake states in $\mathrm{HDC}+/+$ and HDC $-/-$ mice. The curves show the mean hourly cumulative values ( $\pm \mathrm{SE}$ ) during the $7 \mathrm{hr}$ after injection of $\alpha-\mathrm{FMH}(50 \mathrm{mg} / \mathrm{kg}$, i.p., at 4:00 P.M.) ( filled symbols) or saline (unfilled symbols). Note the progressive decrease in wakefulness $(W)$ and increase in both slow wave sleep $(S W S)$ and paradoxical sleep (PS) in the HDC $+/+$ mice (left traces) but not the HDC $-1-$ mice (right traces) $(n=14$ from 7 pairs of mice; $* p<0.05$, ${ }^{* *} p<0.01$; two-tailed $t$ test after significance in two-way ANOVA for repeated measures).

most HA-immunoreactive cell bodies aggregated in both the ventral and dorsal divisions of the tuberomammillary nucleus (TMn), in the adjacent lateral hypothalamic area, and in the perimammillary and supramammillary areas (Fig. 11). The ventral division of the histaminergic TMn was more compactly organized than the dorsal division. The HA-immunoreactive neurons, estimated to number $2500-3500$ in the whole brain, were medium to large in size $(15 \times 30 \mu \mathrm{m})$, mostly ovoid or polygonal in shape, and possessed two to four prominent, long, thick processes. The majority of the HA-immunoreactive perikarya showed strong immunoreactivity, although a few were moderately stained (Fig. 11).

HA-immunoreactive fibers and terminal-like dots were detected in virtually all brain regions. For example, numerous fine varicose fibers were present in the various neocortical areas, hippocampal formation, basal forebrain, thalamus, preoptic/anterior and posterior hypothalamus including the perifornical area, and the forebrain and brainstem aminergic and cholinergic struc- tures, such as the substantia innominata, ventral tegmental area of Tsai, mesopontine tegmentum, raphe nuclei, and locus coeruleus (Figs. 11, 12). Omission of anti-HA antibody or pre-incubation of the sections with excess exogenous free or ovalbumin-conjugated HA resulted in no immunolabeling of any part of the mouse brain (data not shown), demonstrating the specificity of labeling. Examples of the presence of HA-immunoreactive fibers in some of these structures are shown in Figure 12.

HDC $-1-$ mice

In contrast to the dense HA immunoreactivity present in the $\mathrm{HDC}+/+$ brains, no HA immunostaining was found throughout the HDC-/- brains using either immunofluorescent or PAP techniques, and no HA-immunoreactive perikarya, dendrites, fibers, or terminal-like dots were identified in the TMn and the adjacent posterior hypothalamus or elsewhere in the brain (Figs. 11, 12).

Because the lack of the neurotransmitter, HA, TMn neurons in HDC-/- mice can no longer be qualified as histaminergic neurons. However, as demonstrated by neutral red counterstaining (Fig. 12) or immunohistochemistry of type B monoamine oxidase (data not shown), a marker for TMn neurons (Lin et al., 1993), both dorsal and ventral divisions of the TMn, although nonimmunoreactive with anti-HA antibody, seemed to be intact in these mice, without obvious visual difference in either the number of neurons or their morphology (see example from the ventral division in Fig. 12). Finally, no visually apparent structural changes were seen in the brain sections examined. Because the number and morphology of TMn neurons under the light microscopy appeared to be unchanged in $\mathrm{HDC}-/-$ mice, the nature of the functional change after HDC disruption and the neurotransmitter(s), if any, which replaces HA remains to be determined.

\section{Summary of the principal findings}

The present study reveals the absence of detectable brain HAimmunoreactive neurons and the absence of response to administration of HA-related agents in the PCR-confirmed HDC-/mice. Moreover, we have shown that the sleep-wake cycle of these mice was affected both quantitatively and qualitatively. On the one hand, these mice exhibited an increase in the daily amount of PS $(+23 \%)$ and a deficit in W just before and after lights-off. On the other hand, their cortical-EEG showed a reduced SWS/W power ratio and a significant increase in $\delta$ frequencies $(0.8-2.5 \mathrm{~Hz})$ and a deficit of $\theta$-rhythms $(3-9 \mathrm{~Hz})$ during $\mathrm{W}$. These changes are likely to have an effect on the animal's behavior, because the HDC-/- mice presented clear signs of sedation, manifested as a significant decrease in sleep latencies after several behavioral stimuli, and more importantly, unlike normal mice, in being unable to remain awake in a new environment.

\section{DISCUSSION}

Several lines of evidence from our study indicated that the cortical EEG and behavioral signs seen in $\mathrm{HDC}-/-$ mice are caused by the lack of HA synthesis. First, the mouse strain, sex, and age and the experimental conditions were identical for the wild-type and $\mathrm{KO}$ mice, and the only correlation with the observed effects was with the mouse genotype. Because our study used inbred mice, the genomic background of the two genotypes was identical, except for the HDC gene. The small interindividual SDs for the sleep-wake stages within genotype also indicated that each group was homogenous (Fig. 1). Second, in $\mathrm{HDC}+/+$ mice, $\alpha$-FMH (HDC inhibitor) produced the same changes seen in untreated 


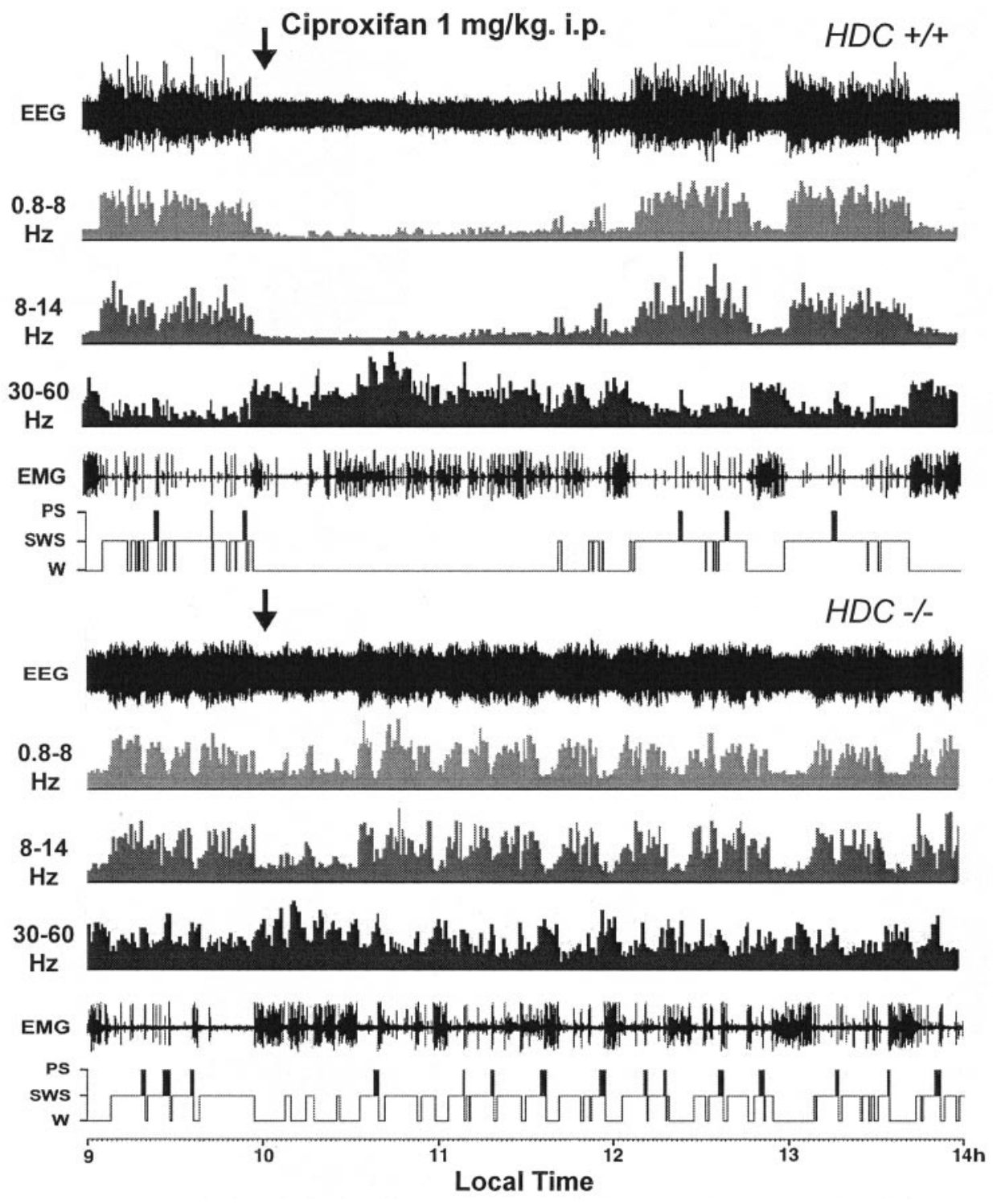

Figure 8. Effects of ciproxifan on cortical EEG and sleep-wake states in $\mathrm{HDC}+/+$ and $\mathrm{HDC}-/-$ mice. Top traces, $\mathrm{HDC}+/+$ mice; bottom traces, HDC-/- mice. Examples of polygraphic recordings, cortical EEG power density (in square microvolts) in different frequency bands, and the corresponding hypnograms illustrating suppression of cortical EEG power at $0.8-8(\theta+\delta)$ and 8-14 $(\alpha) \mathrm{Hz}$, marked enhancement of cortical fast rhythm $(\beta+\gamma, 30-60 \mathrm{~Hz})$, and a waking state induced by injection of ciproxifan $(1 \mathrm{mg} / \mathrm{kg}$, i.p, at 10:00 A.M., indicated by the arrow) in an $\mathrm{HDC}+/+$ mouse but not in an $\mathrm{HDC}-/-$ mouse.
HDC $-/-$ mice, whereas ciproxifan (H3 receptor antagonist that enhances HA transmission; Ligneau et al.,1998) elicited cortical activation. Both drugs had no effect in $\mathrm{HDC}-/-$ mice, indicating their dependence on the availability of HDC and endogenous $\mathrm{HA}$, which are lacking in $\mathrm{HDC}-/-$ mice. Although, because of absorption from the digestive tract, trace amounts of HA may be present in the HDC-/- brain (Ohtsu et al., 2001), this is likely to be non-neuronal and outside the blood-brain barrier, because HA does not pass through the barrier (Schwartz et al., 1991) and because histaminergic cells were not detectable in the TMn and throughout the $\mathrm{HDC}-/-$ brain, indicating the absence of neuronal-HA. Finally, peripheral injection of HA had no effect on either the EEG or sleep-wake cycle in either genotype, indicating that cortical arousal did not depend on peripheral HA. These results, together with the established role of histaminergic neurons in arousal, leave little doubt that the loss of HA from TMn cells is responsible for the effects on the cortical EEG and behavioral states in HDC- $/-$ mice.

\section{Histaminergic neurons and spontaneous waking}

Like other KO-mice that are viable and develop normally, e.g., those lacking orexin (Chemelli et al., 1999), 5HT1B receptors
(Boutrel et al., 1999), or HA-H1-receptors (Lin et al., 2001, 2002), the HDC-/- mice exhibited a circadian rhythm characteristic of rodents. Moreover, there is no major change in the daily amount of spontaneous $\mathrm{W}(<-15 \% / 24 \mathrm{hr})$ in any of the above $\mathrm{KO}$ mice, even though each of the abolished systems is thought to regulate $\mathrm{W}$. These results suggest that, in these mice, the molecular mechanisms and neuronal substrates essential to sleep-wake alternation are not fundamentally impaired by the disruption, during early-embryogenesis, of a gene regulating sleep-waking and that brain plasticity functions in such a way that an adaptive mechanism is already elaborated during early-ontogenesis of the sleepwake cycle to compensate for the functional loss. Although chronic abolition is quite different to acute destruction in terms of brain plasticity, these results are comparable to those obtained by lesioning. Indeed, destruction of one of the brain structures involved in cortical activation causes a transient reduction in $\mathrm{W}$ and quite prompt restoration of approximately normal sleep-wake cycle (Villablanca, 1974; Buzsaki et al., 1988; Vanderwolf and Stewart, 1988; Webster and Jones, 1988; Denoyer et al., 1991). W is a functional state allowing the performance of vital behavior and high brain functions. The maintenance of the cerebral cortex 

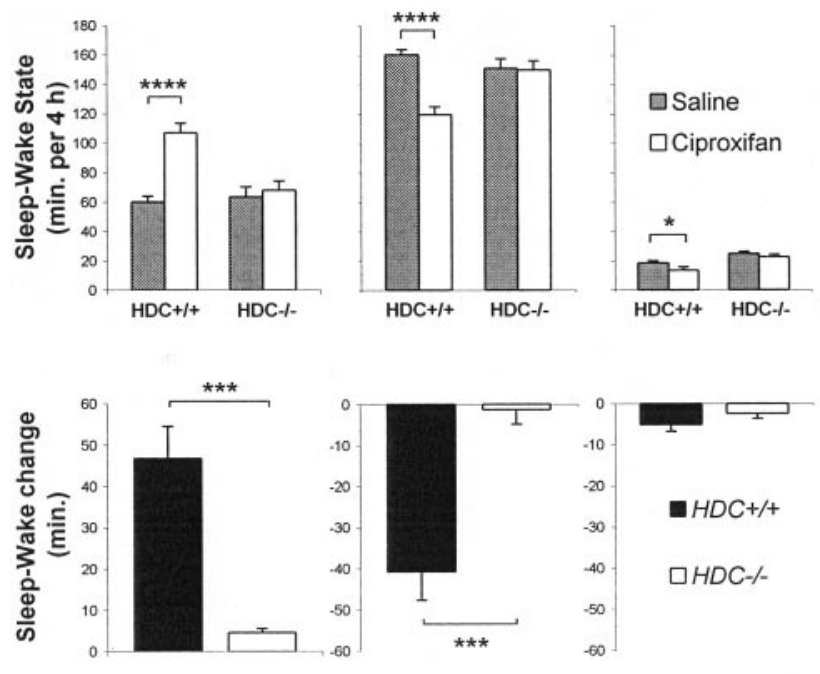

W

SWS

PS

Figure 9. Quantitative variations in sleep-wake states in $\mathrm{HDC}+/+$ and HDC $-/-$ mice after ciproxifan injection. Top histogram, Mean values ( $\pm \mathrm{SE}$, in minutes) of each sleep-wake stage after injection of saline (control) or ciproxifan (1 mg/kg, i.p., at 10:00 A.M.). Bottom histograms, Sleep-wake changes (in minutes) relative to the baseline value for the same group. Note the significant increase in waking $(W)$ and decrease in slow wave sleep $(S W S)$ in HDC $+/+$ mice compared with either their own baseline values or those of HDC $-1-$ mice $\left(n=9\right.$; for both). ${ }^{*} p<0.05$; $* * * p<0.001 ; * * * p<0.0001$, two-tailed $t$ test $)$.

in this highly complex state necessitates the convergent and divergent activity of a large ascending network extending from the medulla to the forebrain and involving several neurotransmitters (Moruzzi, 1972; Steriade, 1991; McCormick, 1992; Jones, 2000; Lin, 2000). Although it is generally presumed that a chronic loss of one system could be compensated by increased activity of the others to maintain a behavioral state as important as $\mathrm{W}$, the mechanisms involved remain unknown.

Despite the lack of major quantitative change in the daily spontaneous $\mathrm{W}$, qualitative aspects of $\mathrm{W}$ in $\mathrm{HDC}-/-$ mice were markedly affected. First, during W, these mice exhibited increased power in $\delta$ rhythms, the most important sign of cortical inactivation occurring predominantly during natural SWS. Second, they also presented a deficit of $\theta$ power, most markedly during W. There is agreement that $\theta$ rhythms recorded from the rodent frontoparietal neocortex are originally propagated from the hippocampus (Welsh et al., 1985) and that hippocampal $\theta$ rhythms during W constitute the most important EEG sign of an attentive state (Bland, 1986). This deficit of $\theta$ activity suggests that in normal mice the heavy HA-neuronal inputs to the supramamillary/septal/hippocampal axis (Inagaki et al., 1988; Panula et al., 1989; Lin et al., 1993), crucially involved in $\theta$ oscillation (Vertes, 1981; Kirk et al., 1996), play an important role in its genesis, whereas, in HDC-/- mice, it suggests that the dysfunction of these HA afferents is not compensated by other mecha- nisms regulating hippocampal $\theta$ activity, like cholinergic neurons (Vanderwolf, 1992). Interestingly, the decrease in $\theta$ rhythms seen in $\mathrm{HDC}-/-$ mice was much greater during $\mathrm{W}$ than during PS, during which the decrease failed to reach statistical significance, suggesting that nonhistaminergic mechanisms predominantly control this activity during PS. This deficit of $\theta$ rhythms, together with increased $\delta$ power, indicates impaired quality of $\mathrm{W}$ in HDC-/- mice, e.g., incomplete cortical activation and decreased vigilance. Finally, these mice had shorter W episodes, notably around lights-off, indicating a handicap to maintain $\mathrm{W}$ duration. Thus, rodents anticipate darkness with increased $\mathrm{W}$ and locomotion, features that were markedly attenuated in $\mathrm{HDC}-/-$ mice. These data, together with an increased release and turnover of brain HA around lights-off (Orr and Quay, 1975; Schwartz et al., 1991; Mochizuki et al., 1992) demonstrate a role of brain HA in enhancing $\mathrm{W}$ and activity at the light/dark shift.

\section{Qualitative aspects of SWS and SWS/W alternation in HDC-/- mice}

Numerous studies indicate that the duration and EEG power of SWS depend on the qualitative-quantitative aspects of previous W episodes (Tobler and Borbély, 1986; Borbély and Achermann, 2000; Tobler, 2000). Indeed, HDC-/- mice showed not only impaired W, but also damaged SWS, which was manifested as a sleep fragmentation, a reduced EEG amplitude and $\theta$ frequencies, and an increase in cortical fast rhythms, contrasting with a decrease during normal SWS. Because $\theta$ frequencies during SWS, as components of slow waves $(0.8-5 \mathrm{~Hz})$, have a different significance to $\theta$ waves during $\mathrm{W}$, its decrease during SWS, together with the reduced EEG amplitude and increased fast rhythms, can be considered as signs of less cortical inactivation. Both the impaired cortical activation during $\mathrm{W}$ and incomplete deactivation during SWS in HDC-/- mice indicated a less clear statedependent change across the sleep-wake cycle and reduced differentiation between SWS and W. Indeed, untreated HDC-/mice and $\alpha$-FMH-treated HDC $+/+$ mice exhibited a significant decrease in the EEG SWS/W power ratio. Thus, disruption of HA synthesis seems to remove a system powerful enough to make contrast between SWS and W. Because the most commonly accepted function for SWS/cortical synchronization is rest and recuperation at the whole organism and cellular levels, we hypothesize that incomplete cortical activation during previous $\mathrm{W}$ episodes leads to poor quality of SWS, which, in turn, deteriorates brain activity and excitability during subsequent $\mathrm{W}$ episodes.

\section{Posterior hypothalamus, histaminergic cells, and hypothalamic regulation of paradoxical sleep}

The posterior hypothalamus has been suggested to exert control on PS by its massive projections to the mesopontine tegmentum (Sakai et al., 1983, 1990), involved in PS generation (Jouvet, 1972; Steriade and McCarley, 1990). Indeed, posterior hypothalamic lesion or inactivation in cats causes transient hypersomnia in PS, with narcoleptic attacks (Sallanon et al., 1988; Lin et al., 1989). The identification of HA neurons in the TM region has allowed

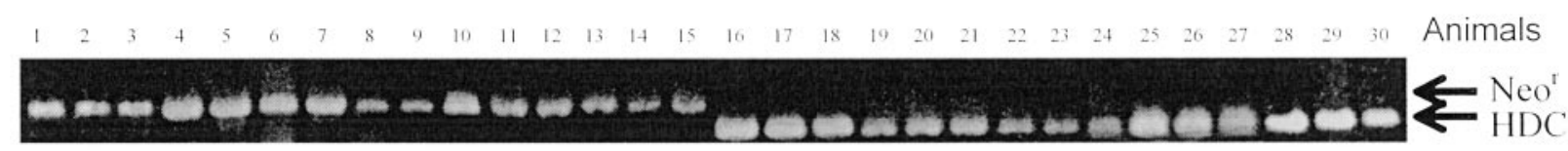

Figure 10. PCR confirmation of genotypes. Lanes 1-15, HDC-/- mice; lanes 16-30, HDC+/+ mice. Note that all HDC $+/+$ mice displayed a 147 bp

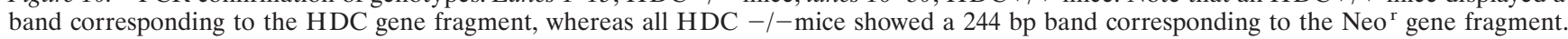




\section{HDC +/+}
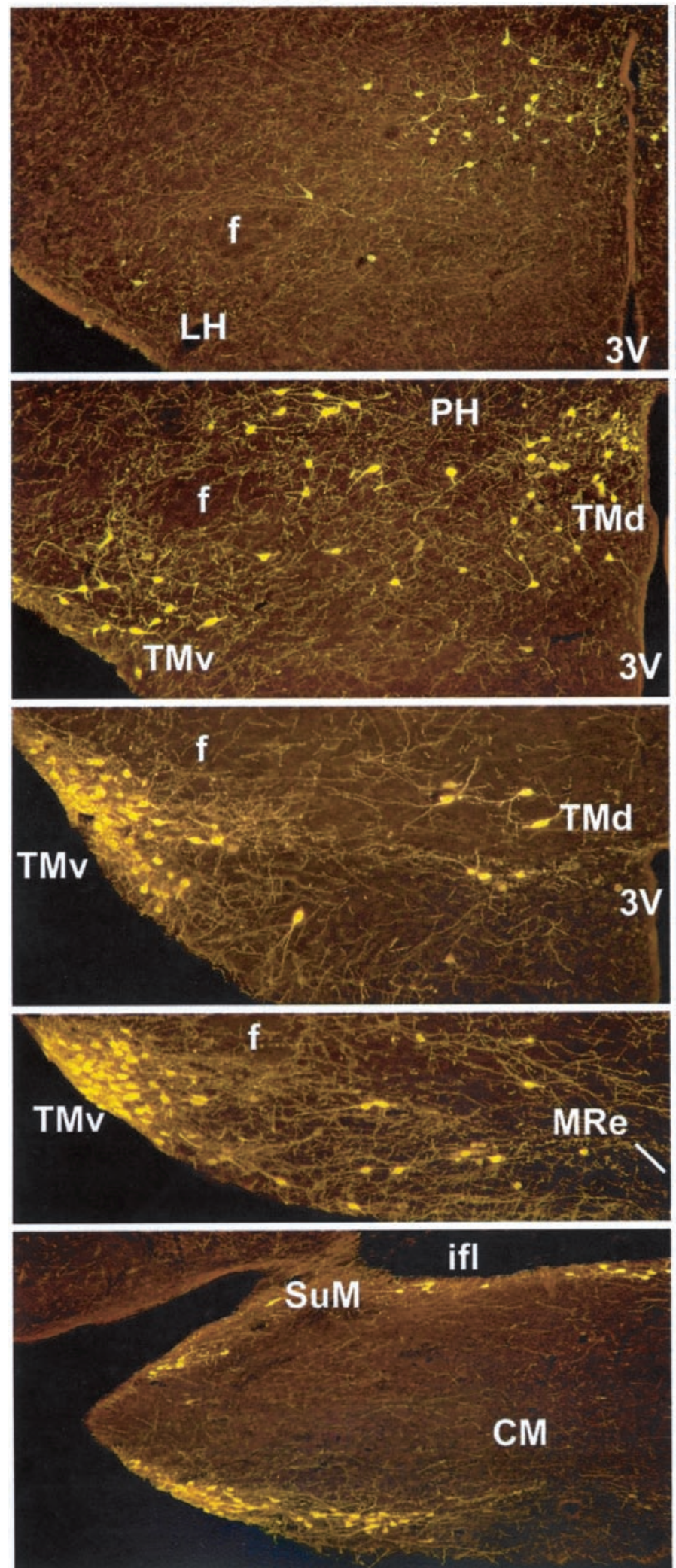

\section{HDC -/-}

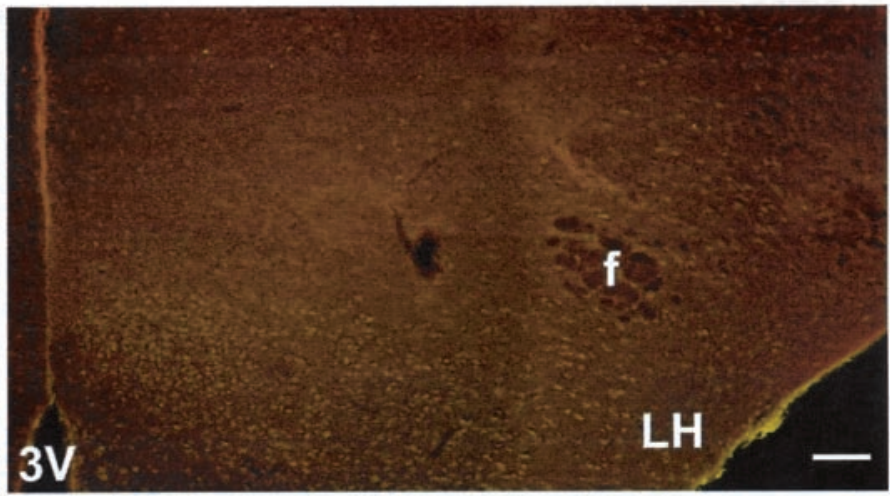

PH

f

TMd

TMv

\section{f}

\section{TMd}

$3 V$

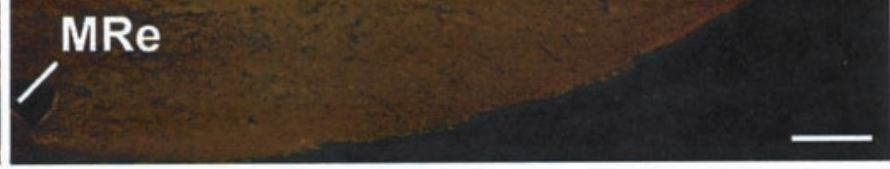

ifl

\section{SuM}

\section{CM}

Figure 11. Distribution of histamine-immunoreactive (HA-IR) neurons in the mouse hypothalamus. Photomicrographs of frontal sections showing HA-IR neurons in the mouse hypothalamus visualized using the immunofluorescent $\mathrm{Cy}^{\mathrm{TM}} 3$ method. Note the presence of HA-IR cell bodies and fibers in the $\mathrm{HDC}+/+$ mouse brain (left) and their absence in the $\mathrm{HDC}-/-$ mouse (right). $3 \mathrm{~V}$, Third ventricle; $C M$, mammillary corpus; $f$, fornix; ipf, interpeduncular fossa; $L H$, lateral hypothalamic area; Mre, mammillary recess; PH, posterior hypothalamic area; SuM, supramammillary area; TMv and $T M d$, tuberomammillary nucleus, ventral and dorsal divisions. Scale bars, $100 \mu \mathrm{m}$. 

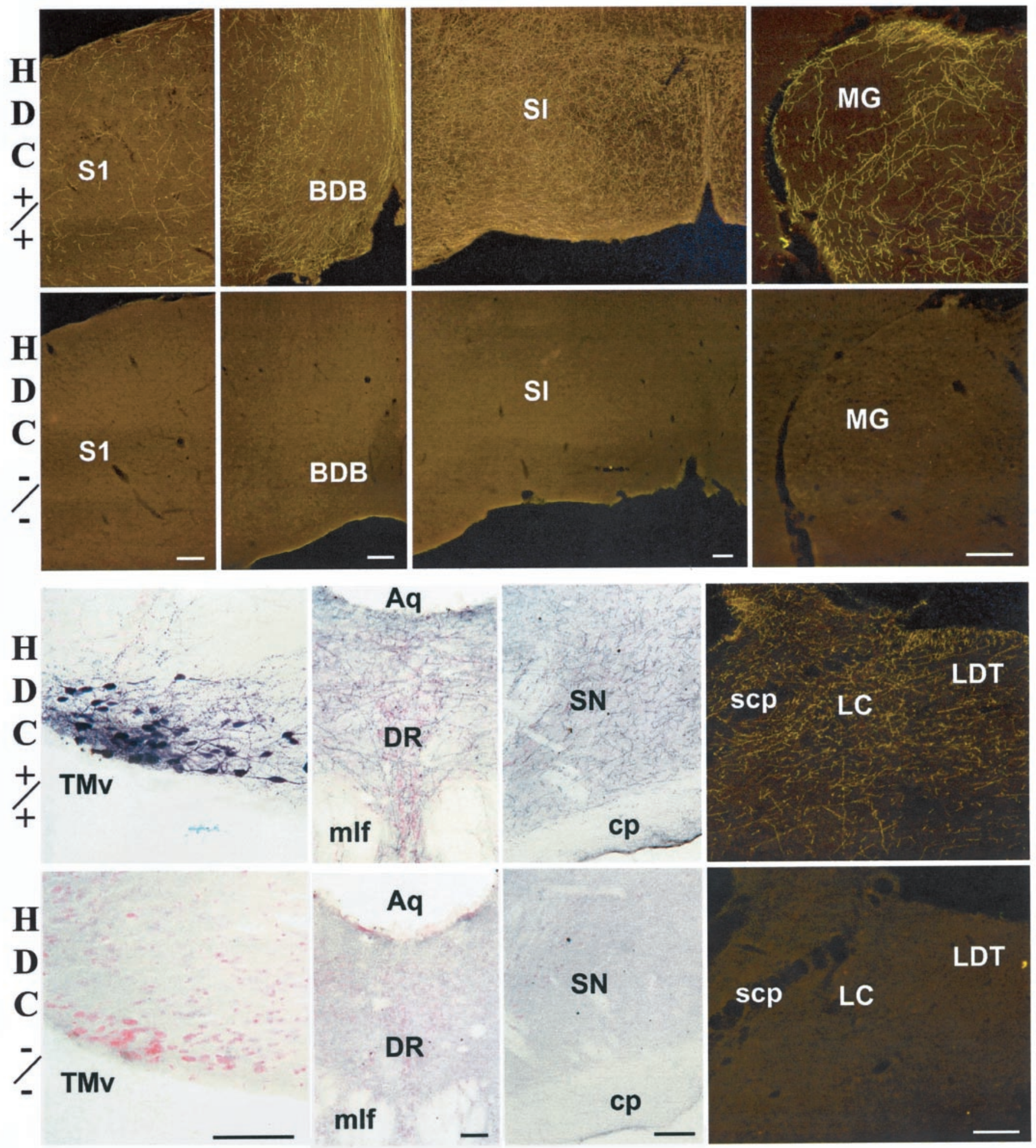

Figure 12. Distribution of histamine-immunoreactive (HA-IR) cell bodies and fibers in the mouse CNS. Photomicrographs of frontal sections showing HA immunoreactivity visualized using immunofluorescent $\mathrm{Cy}^{\mathrm{TM}_{3}}$ (dark-field photomicrographs) or PAP (light-field photomicrographs of sections counterstained with neutral red). Note, in $\mathrm{HDC}+/+$ mice, but not HDC $-/-$ mice, the presence of HA-IR fibers in the primary somatosensory cortex $(S 1)$, the diagonal band of Broca $(B D B)$, and the substantia innominata $(S I)$ of the basal forebrain, the geniculate nucleus of the thalamus $(M G)$, and brainstem structures, such as the dorsal raphe nucleus $(D R)$, substantia nigra $(S N)$, locus coeruleus $(L C)$, and laterodorsal tegmental nucleus $(L D T)$. Also note the presence of HA-IR neurons in the brain section through the tuberomammillary nucleus (TMv) in the HDC $+/+$ mouse but not the HDC-/mouse. Aq, Aqueduct of Sylvius; $m l f$, medial longitudinal fasciculus; $c p$, cerebral peduncle; scp, superior cerebellar peduncle. Scale bars, $100 \mu \mathrm{m}$. 
the assumption that this control could be, in part, histaminergic. This hypothesis has not yet been proven, because posterior hypothalamic lesion or inactivation causes larger increase in SWS than in PS and because the use of various pharmacological agents impairing HA transmission produces an increase in SWS, but not in PS (Lin et al., 1988; Monti et al., 1988; Lin, 2000). In this study, the most marked quantitative change seen with HDC gene disruption was an increase in PS. Inhibition of HA synthesis by $\alpha$-FMH in $\mathrm{HDC}+/+$ mice also enhanced PS. Whereas it remains to determine whether the previous negative results on PS were caused by incomplete inactivation of or limited selectivity of the drugs used for the HA system or whether histaminergic regulation of PS is more pronounced in mice than in other species, the enhanced SP seen here is consistent with the PS-off discharge pattern of presumed HA neurons, which, like other aminergic cells, cease firing during PS (Sakai et al., 1990). Our results thus point out that HA cells are involved in PS-permissive mechanisms and, together with other data (Sakai et al., 1990; Lin, 2000), suggest that HA-cells exert a control, via their descending inputs, over the mesopontine PS-generating mechanisms.

In view of the presence of orexin neurons adjacent to the TMn and given the role of orexin deficiency in narcolepsy, the hypothalamic mechanisms controlling PS should be multiple and include both HA and orexin neurons, which might act in a synergistic complementary manner and which might explain, in part, the importance of the posterior hypothalamus in sleep-wake control. Indeed, HDC and orexin KO mice exhibit a similar increase in PS. However, the increase in $\mathrm{HDC}-1-$ mice is seen during light phase, whereas that in orexin $\mathrm{KO}$ mice occurs during darkness, accompanied by narcoleptic phases (Chemelli et al., 1999). Narcolepsy was not seen either in HDC $-/-$ mice or in normal animals treated with compounds impairing HA transmission. Thus, the narcoleptic phases seen after posterior hypothalamic lesion or inactivation (Sallanon et al., 1988; Lin et al., 1989), which also involved the perifornical area containing orexin cells, should result from a loss of orexin cells rather than HA neurons, whereas the decreased HA transmission seen in narcoleptic dogs (Nishino et al., 2001) would account for their excessive sleep, rather than for narcolepsy. Some interactions between HA and orexin neurons have been identified. Orexin neurons constitute important excitatory afferents to HA neurons (Peyron et al., 1998; Eriksson et al., 2001; Marcus et al., 2001). The arousing effect of orexin seems to depend on H1 receptors (Huang et al., 2001). However, the role of histaminergic inputs to orexin neurons remains unknown. In view of dense histaminergic fibers and terminal dots (Inagaki et al., 1988; Panula et al., 1989; Lin et al., 1993) and H1 receptors (Bouthenet et al., 1988) in the perifornical area, and considering the excitatory action of $\mathrm{H} 1$ receptors (McCormick, 1992; Brown et al., 2001), we hypothesize that HA neurons also excite orexin cells during $\mathrm{W}$ and that the reciprocal excitatory interactions between HA and orexin neurons constitute important hypothalamic arousal mechanisms. Their interaction during PS, however, remains to be determined, because HA cells are silent during this sleep stage.

\section{Histaminergic neurons and maintenance of waking faced with behavioral challenges}

The impaired cortical EEG in HDC-/- mice might be expected to have behavioral consequence. Indeed, they presented signs of somnolence (reduced sleep latencies, e.g.) after routine change of litter or simulation of injection. This decreased arousal reaction in response to external stimuli is consistent with their deficit of $\mathrm{W}$ at lights-off under unstimulated conditions. Moreover, HDC-/mice placed in a new environment failed to remain awake, demonstrated by a significant decrease in sleep latencies and in W duration. Obviously, in the new environment, exploration and other behaviors (curiosity, e.g.) of $\mathrm{HDC}-/-$ mice should also be affected, and this seems to be attributable to their inability to remain vigilant, rather than to a direct effect of loss of HA on specific behaviors, because this sedation was seen in several tests. These results are consistent with the well known drowsiness and impaired performance caused by $\mathrm{H} 1$ receptor antagonists (Douglas, 1985; Nicholson and Stone, 1986; Schwartz et al., 1991; Yanai et al., 1999). Although, by as yet unknown compensatory mechanisms, HDC $-/-$ mice can reach, under normal conditions, a similar daily amount of $\mathrm{W}$ to normal mice, thus allowing the performance of behaviors indispensable for survival, this is by no means apparent under other circumstances. Thus, when a high level of vigilance is required, e.g., lights-off or environmental change, they are unable to maintain awake. Because $\mathrm{W}$ is the basis for all other high brain functions, like attention, performance, and learning, and because an alert waking state is a prerequisite condition for responding to behavioral-cognitive challenges, we suggest that the high brain functions of $\mathrm{HDC}-/-$ mice should also be secondarily affected.

Our findings thus extend the current understanding of the role of HA neurons, which cannot simply be regarded as a system in which neuronal activity is positively linked with instantaneous cortical activation of W. Long-term abolition of HA synthesis impairs cortical EEG, affects all sleep-wake states, and causes behavioral deficits. We suggest that, in addition to their importance in arousal under normal conditions (see introductory remarks), histaminergic neurons also play a key role in maintaining the brain in an awake state in the presence of behavioral challenges.

\section{REFERENCES}

Airaksinen MS, Panula P (1988) The histaminergic system in the guinea pig central nervous system: an immunocytochemical mapping study using an antiserum against histamine. J Comp Neurol 273:163-186.

Airaksinen MS, Alanen S, Szabat E, Visser TJ, Panula P (1992) Multiple neurotransmitters in the tuberomammillary nucleus: comparison of rat, mouse, and guinea pig. J Comp Neurol 323:103-116.

Bland BH (1986) The physiology and pharmacology of hippocampal formation theta rhythms. Prog Neurobiol 26:1-54.

Borbély AA, Achermann P (2000) Sleep homeostasis and models of sleep regulation. In: Principles and practice of sleep medicine (Kryger MH, Roth T, Dement WC, eds), pp 377-390. Philadelphia: Saunders.

Bouthenet ML, Ruat M, Sales N, Garbarg M, Schwartz JC (1988) A detailed mapping of histamine H1-receptors in guinea-pig central nervous system established by autoradiography with [125I]iodobolpyramine. Neuroscience 26:553-600.

Boutrel B, Franc B, Hen R, Hamon M, Adrien J (1999) Key role of 5 -HT1B receptors in the regulation of paradoxical sleep as evidenced in 5-HT1B knock-out mice. J Neurosci 19:3204-3212.

Brown RE, Stevens DR, Haas HL (2001) The physiology of brain histamine. Prog Neurobiol 63:637-672.

Buzsaki G, Bickford RG, Ponomareff G, Thal LJ, Mandel R, Gage FH (1988) Nucleus basalis and thalamic control of neocortical activity in the freely moving rat. J Neurosci 8:4007-4026.

Chemelli RM, Willie JT, Sinton CM, Elmquist JK, Scammell T, Lee C, Richardson JA, Williams SC, Xiong Y, Kisanuki Y, Fitch TE, Nakazato M, Hammer RE, Saper CB, Yanagisawa M (1999) Narcolepsy in orexin knock-out mice: molecular genetics of sleep regulation. Cell 98:437-451.

de Lecea L, Kilduff TS, Peyron C, Gao X, Foye PE, Danielson PE, Fukuhara C, Battenberg EL, Gautvik VT, Bartlett FS, Frankel WN, van den Pol AN, Bloom FE, Gautvik KM, Sutcliffe JG (1998) The hypocretins: hypothalamus-specific peptides with neuroexcitatory activity. Proc Natl Acad Sci USA 95:322-327.

Denoyer M, Sallanon M, Buda C, Kitahama K, Jouvet M (1991) Neurotoxic lesion of the mesencephalic reticular formation and/or the posterior hypothalamus does not alter waking in the rat. Brain Res 539:287-303. 
Douglas WW (1985) Histamine and 5-hydroxytryptamine (serotonin) and their antagonists. In: The pharmacological basis of therapeutics (Gilman AG, Goodman LS, Rall TW, Murad F, eds), pp 605-638. New York: Macmillan.

Eriksson KS, Sergeeva O, Brown RE, Haas HL (2001) Orexin/hypocretin excites the histaminergic neurons of the tuberomammillary nucleus. J Neurosci 21:9273-9279.

Franken P, Malafosse A, Tafti M (1998) Genetic variation in EEG activity during sleep in inbred mice. Am J Physiol 275:1127-1137.

Franken P, Malafosse A, Tafti M (1999) Genetic determinants of sleep regulation in inbred mice. Sleep 22:155-169.

Franklin KB, Paxinos G (1996) The mouse brain in stereotaxic coordinates. San Diego: Academic.

Garbarg M, Barbin G, Rodergas E, Schwartz JC (1980) Inhibition of histamine synthesis in brain by alpha-fluoromethylhistidine, a new irreversible inhibitor: in vitro and in vivo studies. J Neurochem 35:1045-1052.

Haas HL (1992) Electrophysiology of histamine-receptors. In: The histamine receptors (Schwartz JC, Haas HL, eds), pp 161-178. New York: Wiley-Liss.

Hara J, Beuckmann CT, Nambu T, Willie JT, Chemelli RM, Sinton CM, Sugiyama F, Yagami K, Goto K, Yanagisawa M, Sakurai T (2001) Genetic ablation of orexin neurons in mice results in narcolepsy, hypophagia, and obesity. Neuron 30:345-354.

Huang ZL, Qu WM, Li WD, Mochizuki T, Eguchi N, Watanabe T, Urade Y, Hayaishi O (2001) Arousal effect of orexin A depends on activation of the histaminergic system. Proc Natl Acad Sci USA 98:9965-9970.

Huber R, Deboer T, Tobler I (2000) Effects of sleep deprivation on sleep and sleep EEG in three mouse strains: empirical data and simulations. Brain Res 857:8-19.

Inagaki N, Yamatodani A, Ando-Yamamoto M, Tohyama M, Watanabe $\mathrm{T}$, Wada H (1988) Organization of histaminergic fibers in rat brain. J Comp Neurol 273:283-300.

Jones BE (2000) Basic mechanisms of sleep-wake states. In: Principles and practice of sleep medicine (Kryger MH, Roth T, Dement WC, eds), pp 134-154. Philadelphia: Saunders.

Jouvet M (1972) The role of monoamines and acetylcholine containing neurons in the regulation of the sleep-waking cycle. Ergebn Physiol 64:166-307.

Kirk IJ, Oddie SD, Konopacki J, Bland BH (1996) Evidence for differential control of posterior hypothalamic, supramammillary, and medial mammillary theta-related cellular discharge by ascending and descending pathways. J Neurosci 16:5547-5554.

Kiyono S, Seo M, Shibagaki M, Watanabe T, Maeyama K, Wada H (1984) Effects of $\alpha$-fluoromethylhistidine on sleep-waking parameters in rats. Physiol Behav 34:615-617.

Kollonitsch J, Perkins LM, Patchett AA, Doldouras GA, Marburg S, Duggan DE, Maycock AL, Aster SD (1978) Selective inhibitors of biosynthesis of aminergic neurotransmitters. Nature 274:906-908.

Ligneau X, Lin JS, Vanni-Mercier G, Jouvet M, Muir JL, Ganellin CR, Stark H, Elz S, Schunack W, Schwartz J (1998) Neurochemical and behavioral effects of ciproxifan, a potent histamine H3-receptor antagonist. J Pharmacol Exp Ther 287:658-666.

Lin JS (2000) Brain structures and mechanisms involved in the control of cortical activation and wakefulness, with emphasis on the posterior hypothalamus and histaminergic neurons. Sleep Med Rev 4:471-503.

Lin JS, Luppi PH, Salvert D, Sakai K, Jouvet M (1986a) Histaminecontaining neurons in the cat hypothalamus. C $\mathrm{R}$ Acad Sci (III) 303:371-376.

Lin JS, Sakai K, Jouvet M (1986b) Role of hypothalamic histaminergic systems in the regulation of the states of vigilance in the cat. C R Acad Sci 303:469-474.

Lin JS, Sakai K, Jouvet M (1988) Evidence for histaminergic arousal mechanisms in the hypothalamus of cat. Neuropharmacology 27: 111-122.

Lin JS, Sakai K, Vanni-Mercier G, Jouvet M (1989) A critical role of the posterior hypothalamus in the mechanisms of wakefulness determined by microinjection of muscimol in freely moving cats. Brain Res 479:225-240.

Lin JS, Kitahama K, Fort P, Panula P, Denney RM, Jouvet M (1993) Histaminergic system in the posterior hypothalamus in the cat with reference to type B monoamine oxidase. J Comp Neurol 330:405-420.

Lin JS, Hou Y, Sakai K, Jouvet M (1996) Histaminergic descending inputs to the mesopontine tegmentum and their role in the control of cortical activation and wakefulness in the cat. J Neurosci 16:1523-1537.

Lin JS, Vanni-Mercier G, Parmentier R (2001) Histaminergic neurons and sleep-wake regulation. In: Histamine research in the new millennium (Watanabe T, Timmerman H, Yanai K, eds), pp 125-135. Amsterdam: Elsevier.

Lin JS, Parmentier R, Valatx JL, Watanabe T (2002) Cortical EEG and sleep-wake cycle in histamine H1-receptor knock-out mice. Soc Neurosci Abstr 28:XXX.

Lin L, Faraco J, Li R, Kadotani H, Rogers W, Lin X, Qiu X, de Jong PJ, Nishino S, Mignot E (1999) The sleep disorder canine narcolepsy is caused by a mutation in the hypocretin (orexin) receptor 2 gene. Cell 98:365-376.

Maeyama K, Watanabe T, Taguchi Y, Yamatodani A, Wada H (1982) Effect of alpha-fluoromethylhistidine, a suicide inhibitor of histidine decarboxylase, on histamine levels in mouse tissues. Biochem Pharmacol 31:2367-2370.

Marcus JN, Aschkenasi CJ, Lee CE, Chemelli RM, Saper CB, Yanagisawa M, Elmquist JK (2001) Differential expression of orexin receptors 1 and 2 in the rat brain. J Comp Neurol 435:6-25.

McCormick DA (1992) Neurotransmitter actions in the thalamus and cerebral cortex and their role in neuromodulation of thalamocortical activity. Prog Neurobiol 39:337-388.

Mochizuki T, Yamatodani A, Okakura K, Horii A, Inagaki N, Wada H (1992) Circadian rhythm of histamine release from the hypothalamus of freely moving rats. Physiol Behav 51:391-394.

Monti JM, D'Angeto L, Jantos H, Pazos S (1988) Effects of $\alpha$-fluoromethylhistidine on sleep and wakefulness in the rat. J Neural Transm 72:141-145.

Monti JM, Jantos H, Boussard M, Altier H, Orellana C, Olivera S (1991) Effects of selective activation or blockade of the histamine $\mathrm{H} 3$ receptor on sleep and wakefulness. Eur J Pharmacol 205:283-287.

Moruzzi G (1972) The sleep-waking cycle. Ergeb Physiol 64:1-165.

Moruzzi G, Magoun HW (1949) Brainstem reticular formation and activation of the EEG. Electroencephalogr Clin Neurophysiol 1:455-473.

Nagy A, Rossant J, Nagy R, Abramow-Newerly W, Roder JC (1993) Derivation of completely cell culture-derived mice from early-passage embryonic stem cells. Proc Natl Acad Sci USA 90:8424-8428.

Nicholson AN, Stone BM (1986) Antihistamines: impaired performance and the tendency to sleep. Eur J Clin Pharmacol 30:27-32.

Nishino S, Fujiki N, Ripley B, Sakurai E, Kato M, Watanabe T, Mignot E, Yanai K (2001) Decreased brain histamine content in hypocretin orexin receptor-2 mutated narcoleptic dogs. Neurosci Lett 313:125-128.

Ohtsu H, Tanaka S, Terui T, Hori Y, Makabe-Kobayashi Y, Pejler G, Tchougounova E, Hellman L, Gertsenstein M, Hirasawa N, Sakurai E, Buzas E, Kovacs P, Csaba G, Kittel A, Okada M, Hara M, Mar L, Numayama-Tsuruta K, Ishigaki-Suzuki S, Ohuchi K, Ichikawa A, Falus A, Watanabe T, Nagy A (2001) Mice lacking histidine decarboxylase exhibit abnormal mast cells. FEBS Lett 502:53-56.

Orr E, Quay WB (1975) Hypothalamic 24-hour rhythms in histamine, histidine decarboxylase and histamine- $N$-methyltransferase. Endocrinology 96:941-945.

Panula P, Yang HY, Costa E (1984) Histamine-containing neurons in the rat hypothalamus. Proc Natl Acad Sci USA 81:2572-2576.

Panula P, Häppolä O, Airaksinen S, Auvinen S, Virkamäki A (1988) Carbodiimide as a tissue fixative in histamine immunohistochemistry and its application in developmental neurobiology. J Histochem Cytochem 36:259-269.

Panula P, Pirvola U, Auvinen S, Airaksinen MS (1989) Histamineimmunoreactive nerve fibers in the rat brain. Neuroscience 28:585-610.

Peyron C, Tighe DK, van den Pol AN, de Lecea L, Heller HC, Sutcliffe JG, Kilduff TS (1998) Neurons containing hypocretin (orexin) project to multiple neuronal systems. J Neurosci 18:9996-10015.

Sakai K, Salvert D, Kimura H, Maeda T, Jouvet M (1983) Ascending and descending projections of caudal hypothalamic neurons stained by serotoine immunohistochemistry after administration of 5-hydroxytriptophan in the cat. C R Acad Sci 296:1013-1018.

Sakai K, El Mansari M, Lin JS, Zhang JG, Vanni-Mercier G (1990) The posterior hypothalamus in the regulation of wakefulness and paradoxical sleep. In: The diphencephalon and sleep (Mancia M, Marini G, eds), pp 171-198. New York: Raven.

Sakurai T, Amemiya A, Ishii M, Matsuzaki I, Chemelli RM, Tanaka H, Williams SC, Richardson JA, Kozlowski GP, Wilson S, Arch JR Buckingham RE, Haynes AC, Carr SA, Annan RS, McNulty DE, Liu WS, Terrett JA, Elshourbagy NA, Bergsma DJ, Yanagisawa M (1998) Orexins and orexin receptors: a family of hypothalamic neuropeptides and $\mathrm{G}$ protein-coupled receptors that regulate feeding behavior. Cell 92:573-585.

Sallanon M, Sakai K, Buda C, Puymartin M, Jouvet M (1988) Increase of paradoxical sleep induced by microinjections of ibotenic acid into the ventrolateral part of the posterior hypothalamus in the cat. Arch Ital Biol 126:87-97.

Schwartz JC, Arrang JM, Garbarg M, Pollard H, Ruat M (1991) Histaminergic transmission in the mammalian brain. Physiol Rev 71:1-51.

Steinbusch HWM, Mulder AH (1984) Immunohistochemical localization of histamine in neurons and mast cells in the rat brain. In: Handbook of chemical neuroanatomy (Björklund A, Hökfelt T, and Kuhar MJ, eds), pp 126-140. Amsterdam: Elsevier.

Steininger TL, Alam MN, Gong H, Szymusiak R, McGinty D (1999) Sleep-waking discharge of neurons in the posterior lateral hypothalamus of the albino rat. Brain Res 840:138-147.

Steriade M (1991) Alertness, quiet sleep, dreaming. In: Cerebral cortex, Vol 9 (Peters A, ed), pp 279-357, New York: Plenum.

Steriade M, Buzsaki G (1990) Parallel activation of thalamic and cortical 
neurons by brainstem and basal forebrain cholinergic system. In: Brain cholinergic systems (Steriade M, Biesold D, eds), pp 3-64, Oxford: Oxford UP.

Steriade M, McCarley RW (1990) Brainstem control of wakefulness and sleep. New York: Plenum.

Tobler I (2000) Phylogeny of sleep regulation. In: Principles and practice of sleep medicine (Kryger MH, Roth T, Dement WC, eds), pp 72-81. Philadelphia: Saunders.

Tobler I, Borbély AA (1986) Sleep EEG in the rat as a function of prior waking. Electroencephalogr Clin Neurophysiol 64:74-76.

Valatx JL (1971) Enregistrement chronique des activités électriques cérébrales, musculaires et oculaires chez la souris. C R Seances Soc Biol Fil 165:112-115.

Valatx JL, Bugat R (1974) Facteurs génétiques dans le determinisme du cycle veille-sommeil chez la souris. Brain Res 69:315-330.

Vanderwolf CH (1992) The electrocorticogram in relation to physiology and behavior: a new analysis. Electroencephalogr Clin Neurophysiol $82: 165-175$.

Vanderwolf CH, Stewart DJ (1988) Thalamic control of neocortical activation: a critical reevaluation. Brain Res Bull 20:529-538.

Vanni-Mercier G, Sakai K, Jouvet M (1984) Specific neurons for wake- fulness in the posterior hypothalamus in the cat. C R Acad Sci III 298:195-200.

Vertes RP (1981) An analysis of ascending brain stem systems involved in hippocampal synchronization and desynchronization. J Neurophysiol 46:1140-1159.

Villablanca J (1974) Role of the thalamus in sleep control: Sleep-wakefulness in chronic diencephalic and athalamic cats. In: Basic sleep mechanisms (Petre-Quadens O, Schlag JD, eds), pp. 51-78. New York: Academic.

Watanabe T, Taguchi Y, Shiosaka S, Tanaka J, Kubota H, Terano Y, Tohyama M, Wada H (1984) Distribution of the histaminergic neuron system in the central nervous system of rats; a fluorescent immunohistochemical analysis with histidine decarboxylase as a marker. Brain Res 295:13-25.

Webster HH, Jones BE (1988) Neurotoxic lesions of the dorsolateral pontomesencephalic tegmentum-cholinergic cell area in the cat. II. Effects upon sleep-waking states. Brain Res 458:285-302.

Welsh DK, Richardson GS, Dement WC (1985) A circadian rhythm of hippocampal theta activity in the mouse. Physiol Behav 35:533-538.

Yanai K, Okamura N, Tagawa M, Itoh M, Watanabe T (1999) New findings in pharmacological effects induced by antihistamines: from PET studies to knock-out mice. Clin Exp Allergy [Suppl 3] 29:29-36. 